\title{
Antropometría aplicada a la interpretación de la arquitectura histórica. El artesonado del Salón de Caballeros XXIV de la Madraza de Granada y las dudas sobre su origen
}

\section{Anthropometry applied to the interpretation of historical architecture. The coffered ceiling in the Salon de Caballeros XXIV of the Madraza of Granada and the doubts about its origin}

\author{
Francisco Javier Roldán Medina ${ }^{1}$ \\ LAAC (Laboratorio de Arqueología y Arquitectura de la Ciudad) \\ Ma Teresa Gómez Galisteo² \\ Investigadora independiente
}

\begin{abstract}
RESUMEN
El análisis con un nuevo método metrológico indica que la construcción del artesonado del Salón de Caballeros XXIV de la Madraza de Granada no se ajusta al momento histórico que siempre le ha sido asignado. Sus dimensiones corresponden con una métrica Nazarí II, y esta información nos lleva a plantear una serie de hipótesis que permitan dar respuesta a esta circunstancia basándonos en los datos históricos conocidos, aunque por ahora la falta de otro tipo de fuentes no permite dar por fehaciente ninguna conclusión y solo deja movernos en el campo de las conjeturas.
\end{abstract}

Palabras clave: historiografía; metrología; datación; madraza Yusufiyya; carpintería; nazarí; mudéjar.

\begin{abstract}
The analysis with a new metrological method indicates that the construction of the coffered ceiling in the Salon de Caballeros XXIV of the Madraza of Granada does not coincide with the historical era that it has been traditionally assigned to it. Its measurements correspond to the Nazari II metric and this information leads us to consider a new series of hypotheses intended to respond to this circumstance, basing our assessments on known historical data. However, the current lack of other sources limits our capacity to arrive at any reliable conclusions, allowing us just to propose assumptions on the matter.
\end{abstract}

Key words: historiography; metrology; dating; Yusufiyya madraza; carpentry; Nasrid; Mudejar.

Recibido: 20-01-2019. Aceptado: 28-03-2019. Publicado online: 28-08-2019

Cómo citar este artículo / Citation

Roldán Medina, F. J., Gómez Galisteo, M. a T. 2019: "Antropometría aplicada a la interpretación de la arquitectura histórica. El artesonado del Salón de Caballeros XXIV de la Madraza de Granada y las dudas sobre su origen", Arqueología de la Arquitectura, 16: e084. https://doi.org/10.3989/ arq.arqt. 2019.006

Copyright: (c) 2019 Consejo Superior de Investigaciones Científicas (CSIC) - Universidad del País Vasco/Euskal Herriko Unibertsitatea (UPV/ EHU). Este es un artículo de acceso abierto distribuido bajo los términos de la licencia de uso y distribución Creative Commons Reconocimiento 4.0 Internacional (CC BY 4.0).

froldan@ugr.es / ORCID iD: https://orcid.org/0000-0002-2158-4936

goga2021@coaatgr.es / ORCID iD: https://orcid.org/0000-0002-2674-1232 


\section{INTRODUCCIÓN}

El Palacio de la Madraza constituye un edificio de singular interés en el contexto de la arquitectura granadina e hispana, cuya historia está íntimamente ligada a la vitalidad del centro histórico de Granada en el Medievo, y la Edad Moderna como núcleo institucional, religioso y civil (Fig. 1). Su nombre deriva de la llamada ya en época medieval madraza Yusufiyya o madraza Nasriyya, fundación realizada el año 1349 bajo el gobierno del sultán nazarí Yusuf I (Fig. 2). Fue esta madraza la primera creada como fundación docente estatal de estas características en al-Andalus (Sarr 2015).

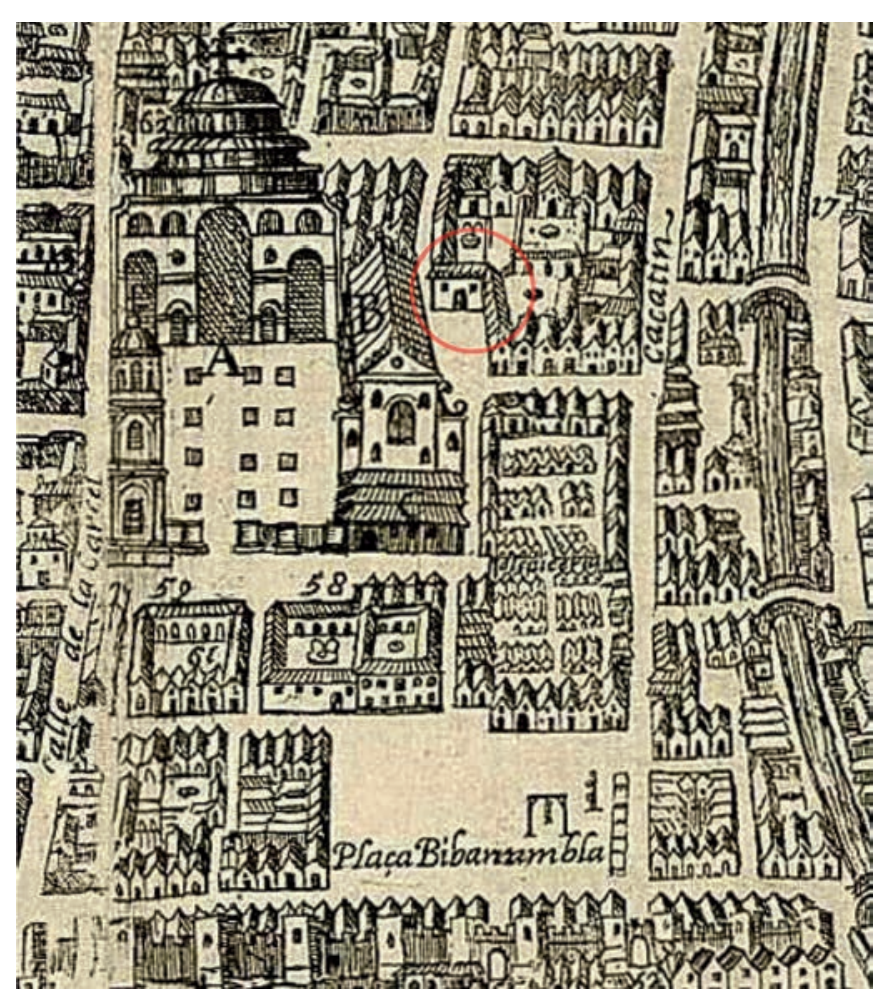

Figura 1. Localización de la Madraza en un detalle de la Plataforma de Vico grabada por Francisco Heylan hacia 1613.

A partir del año 1500 se inicia la segunda etapa histórica del Palacio de la Madraza, momento a partir del cual pasa a denominarse como "Casa del Cabildo", es decir la sede capitular del ayuntamiento o concejo granadino. Este largo devenir histórico mantenido hasta el año 1858 se encuentra jalonado por dos actuaciones de gran empeño en fechas muy diferentes: en primer lugar los años iniciales del Quinientos, que afectaron a la ubicación de amplios espacios de reunión en la crujía de la fachada; y en segundo lugar la década de 1720 , cuyas profundas reformas son las que han condicionado la fisonomía actual del inmueble (Fig. 3), perteneciente en la actualidad a la Universidad de Granada.

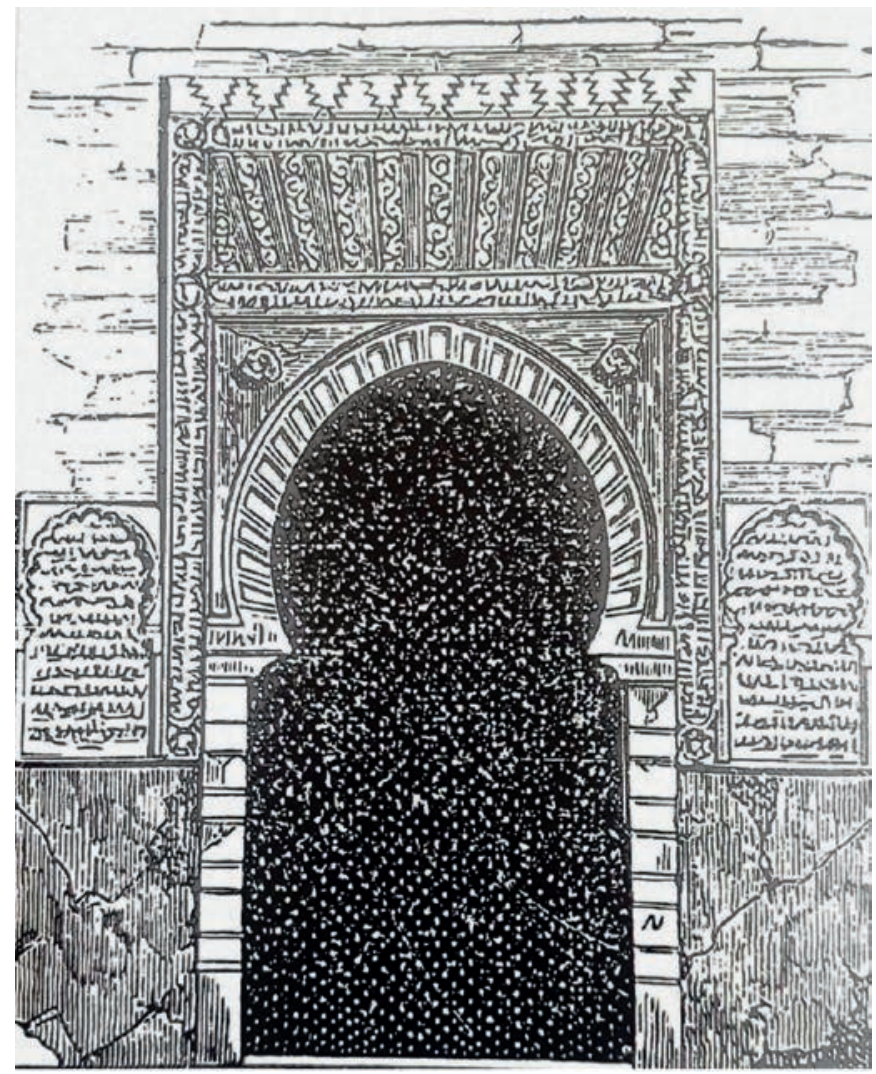

Figura 2. Reconstrucción hipotética de la portada de la Madraza realizada por Rafael Contreras en 1878.

Durante la restauración del edificio realizada en los años 2006 y 2007 se llevó a cabo una excavación arqueológica cuyos resultados permitieron plantear una hipótesis sobre su distribución original (Fig. 4).

En este documento vamos a analizar la evolución constructiva del edificio, pero circunscribiéndonos principalmente a las estancias creadas a inicios del siglo XVI destinadas a ser lugares de reunión, en concreto a sala alta del cabildo denominada Salón de Caballeros XXIV, y principalmente a la armadura o artesonado ${ }^{3}$ que la cubre hasta el presente. Este espacio, según las fuentes documentales consultadas y recogidas en numerosos textos editados, es fruto de las primeras actuaciones de ampliación del edificio islámico en los incipientes años tras la conquista. Por ende la armadura construida para techar esta sala se ha considerado siempre coetánea al cuerpo constructivo en el cual apoya, y consecuentemente ha sido definida en todo momento como un artesonado de estilo mudéjar.

Empleamos aquí la acepción del término Artesonado por extensión a los techos de par y nudillo con testeros (ochavados o no) cuya forma recuerda a una gran artesa (Nuere 1989: 150). 

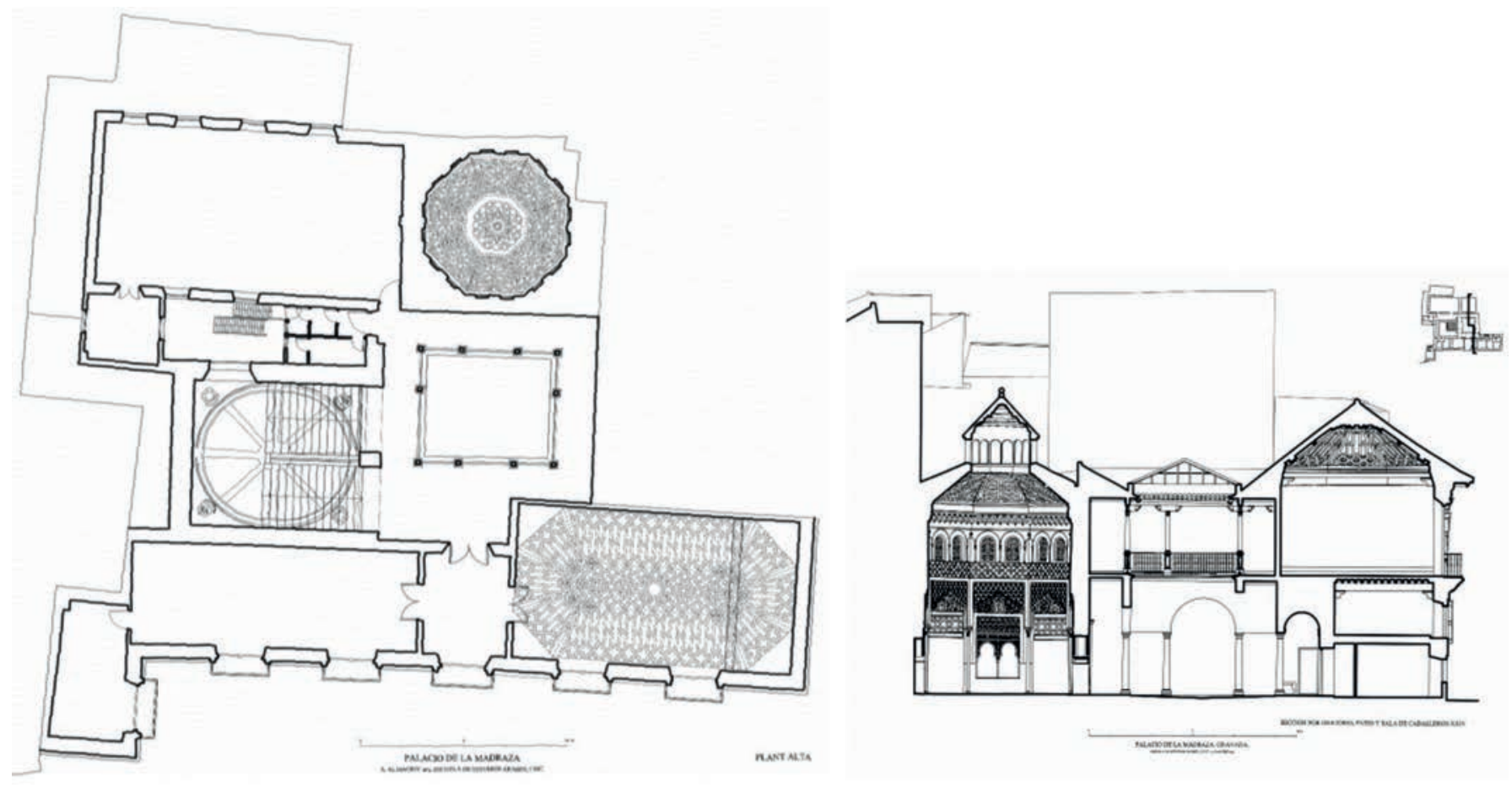

Figura 3. Planta alta y sección (Almagro 2007: 328 -331).
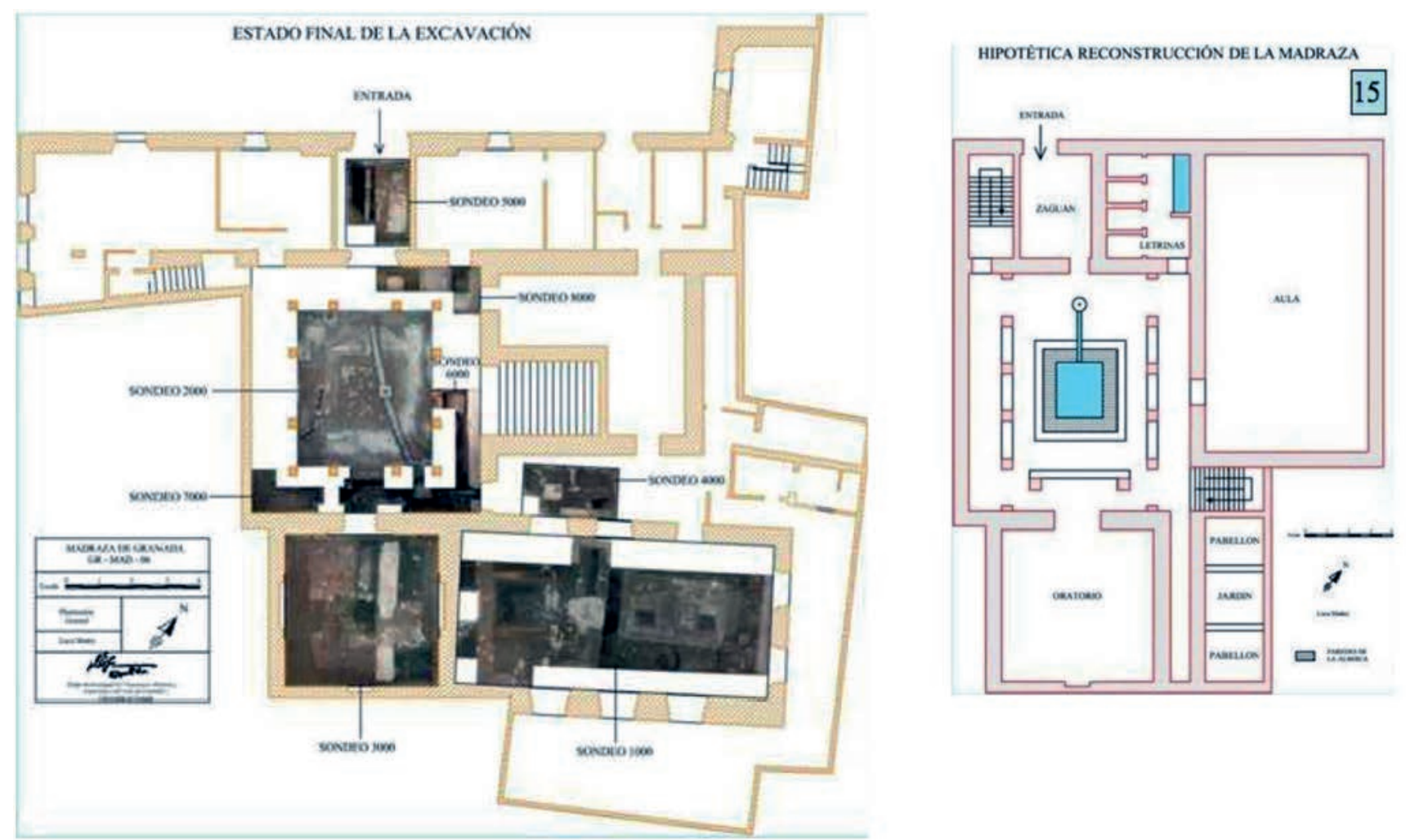

Figura 4. Estado final de la excavación e Hipotética reconstrucción de la Madraza (Mattei 2008: láms. 3-4). 
La ubicación temporal de esta estructura lígnea, hasta el momento tan consensuada, no había podido ser contrastada mediante otra tipología de fuentes. No obstante el avance de las técnicas fotogramétricas facilita su correcto registro geométrico (Fig. 5), así como su interpretación constructiva y métrica-modular.

\section{LAS REGLAS DE LA ARQUITECTURA ANTROPOMÉTRICA}

Tradicionalmente se ha considerado que el esquema metrológico antiguo era similar al actual sistema métrico decimal (SI), en donde en vez del metro como referencia existieron distintos patrones de medida antropométrica que se dividían aritméticamente en fracciones más pequeñas. No obstante hace unos años el estudio detallado de otro edificio granadino, el Cuarto Real de Santo Domingo del siglo XIII, reveló un aspecto sorprendente y desconocido sobre la naturaleza del esquema lógico de su sistema de proporciones. Para definir el tamaño de todos sus módulos constructivos era necesaria y suficiente -además de la escala de fracciones aritméticas duodecimales que componen las unidades antropométricas ordinarias- el uso combinado con otra escala mayorada en la proporción de la diagonal del cuadrado, la raíz cuadrada de dos (Roldán 2011).

El uso de esta regla compositiva mediante lados y diagonales de cuadrado antropométrico -que permite diseños dinámicos de gran complejidad basados en la simetría octogonal- ha sido confirmado en el estudio de numerosas y variadas obras del pasado (Roldán 2014a). La aparente universalidad de esta simple ley armónica ha permitido caracterizar el sistema metrológico (Roldán 2012a, 2012b, 2012c, 2013, 2014b, 2015d, 2015e, 2016) y desarrollar una metodología científica para producir estudios antropométricos del patrimonio que identifican las trazas compositivas y reproducen las unidades de medida teóricas exactas con que se construyeron estas estructuras originalmente (Roldán 2015a, 2015c, 2018a), incluso a partir únicamente de sus restos arqueológicos (Roldán 2015b).
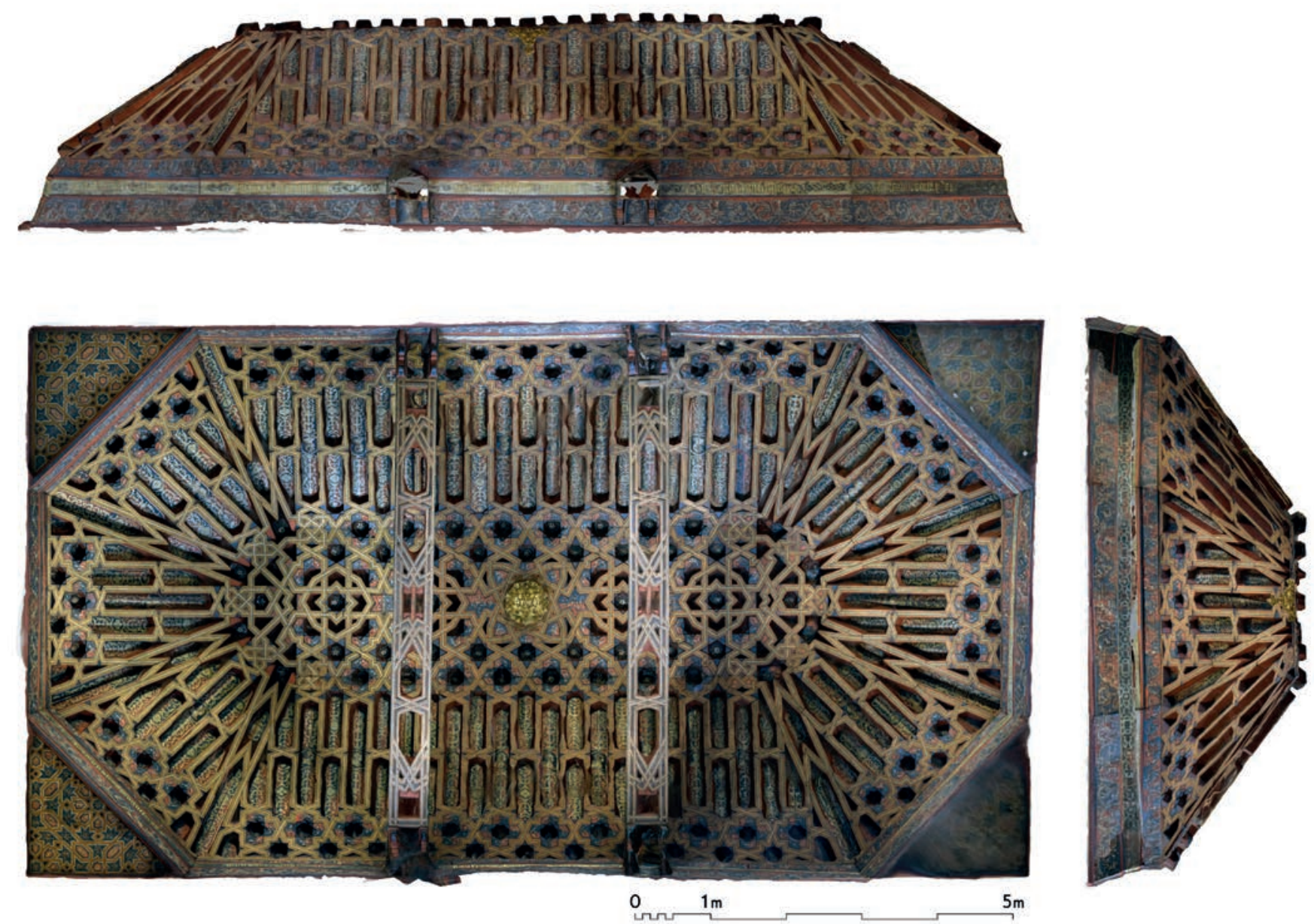

Figura 5. Ortofotos de planta y alzados de la armadura del Salón de Caballeros XXIV de la Madraza de Granada. 
La Antropometría o proceso de arquitectura inversa se realiza sobre la planimetría general de la obra, en la que se insertan y escalan las distintas ortofotos obtenidas de los modelos fotogramétricos de detalle. Este conjunto gráfico constituye la fuente de la investigación del trabajo de gabinete, y sobre ella se exponen los resultados para su contraste.

El método consiste en deducir la distribución de lados y diagonales de cuadrado que rigen las trazas de la obra. Esta premisa implica que las tramas compositivas no se ajustarán por lo general a una cuadrícula regular preestablecida, tal como hacemos en la actualidad al trabajar con el espacio euclídeo puro del SI. La posibilidad de utilizar diagonales en la determinación de longitudes habilita personalizar cualquier trama armónica formada por cuadrados, rectángulos en proporción $\sqrt{2}$ y rectángulos de plata.

A partir de la trama compositiva general se obtiene la dimensión concreta del cuadrado modulador, así como los valores de su diagonal y del resto de unidades antropométricas. Se debe verificar que la medida de cada parte de la obra, grande o pequeña, corresponda con una combinación de lados y diagonales del sistema.
Gráficamente se representa el módulo braza $\mathrm{M}$ con un cuadrado, y sus fracciones antropométricas con escuadras proporcionales. Aquí se ha utilizado el tamaño codo $(\mathrm{M} / 4)$ dividido en 6 palmos, y el tamaño palmo $(\mathrm{M} / 24)$ dividido en 4 dedos. La posición recta o girada $45^{\circ}$ del módulo permite cuantificar el número de lados y diagonales de la composición.

Numéricamente los valores obtenidos son teóricos. Se trata de dimensiones nominales que no coincidirán exactamente con la medida real de la parte, debido a los errores de fabricación y al devenir del tiempo. Como en todo proceso productivo es necesario establecer una tolerancia para la aceptación del resultado. Aquí se ha adoptado el $1 \%$ de desviación sobre el valor nominal, tolerancia admisible en tareas manuales de nueva construcción.

En Granada los resultados obtenidos hasta ahora (Fig. 6) han posibilitado establecer sus últimos periodos métricos. Además de la medida Castellana de la vara de Burgos con que se edificó la mayor parte del casco histórico de Granada en la Edad Moderna, destaca en la construcción del Palacio de Carlos V -y en otras obras de esta ciudad atribuibles al periodo de su reinado- la

\begin{tabular}{|c|c|c|c|c|c|c|c|c|c|c|}
\hline \multicolumn{3}{|c|}{ Periodo MÉTRICO } & \multirow{2}{*}{$\begin{array}{c}\text { NAZARÍI } \\
\text { S. XIII }\end{array}$} & \multirow{2}{*}{$1238-1314$} & \multirow{2}{*}{$\begin{array}{l}\text { NAZARÍ II } \\
\text { S. XIV-XV }\end{array}$} & \multirow{2}{*}{$1314-1492 ?$} & \multirow{2}{*}{\begin{tabular}{|c|} 
TOLEDANA \\
S. XVI \\
\end{tabular}} & \multirow[b]{2}{*}{$1516-1568 ?$} & \multirow{2}{*}{ CASTELLANA } & \multirow[b]{2}{*}{$1492-1888 ?$} \\
\hline Época & Siglo & Años & & & & & & & & \\
\hline FRACCIÓN & UNIDAD & UNIT & $M(\mathrm{~cm})$ & $M+(\mathrm{cm})$ & $\mathrm{M}(\mathrm{cm})$ & $M+(\mathrm{cm})$ & $M(\mathrm{~cm})$ & $M+(\mathrm{cm})$ & $\mathrm{M}(\mathrm{cm})$ & $M+(\mathrm{cm})$ \\
\hline 1 & BRAZA & FATHOM & 208,00 & 294,16 & 181,88 & 257,22 & 174,60 & 246,92 & 167,18 & 236,43 \\
\hline $1 / 2$ & VARA & YARD & 104,00 & 147,08 & 90,94 & 128,61 & 87,30 & 123,46 & 83,59 & 118,21 \\
\hline $1 / 4$ & CODO & CUBIT & 52,00 & 73,54 & 45,47 & 64,30 & 43,65 & 61,73 & 41,80 & 59,11 \\
\hline $1 / 6$ & PIE & FOOT & 34,67 & 49,03 & 30,31 & 42,87 & 29,10 & 41,15 & 27,86 & 39,40 \\
\hline $1 / 8$ & CUARTA & SPAN & 26,00 & 36,77 & 22,74 & 32,15 & 21,83 & 30,87 & 20,90 & 29,55 \\
\hline $1 / 24$ & PALMO & PALM & 8,67 & 12,26 & 7,58 & 10,72 & 7,28 & 10,29 & 6,97 & 9,85 \\
\hline $1 / 96$ & DEDO & DIGIT & 2,17 & 3,06 & 1,89 & 2,68 & 1,82 & 2,57 & 1,74 & 2,46 \\
\hline $1 / 384$ & GRANO & & 0,54 & 0,77 & 0,47 & 0,67 & 0,45 & 0,64 & 0,44 & 0,62 \\
\hline \multicolumn{3}{|c|}{ Obras Alhambra - Generalife } & \multicolumn{2}{|c|}{ Baños de Comares } & \multicolumn{2}{|c|}{ Palacio de Comares } & \multicolumn{2}{|c|}{ Palacio de Carlos V } & \multicolumn{2}{|c|}{ Iglesia Santa Maria } \\
\hline & & & \multicolumn{2}{|c|}{ Palacio del Partal (P.B.) } & \multicolumn{2}{|c|}{ Patio de los Leones } & \multicolumn{2}{|c|}{ Fuente de Carlos V } & \multicolumn{2}{|c|}{ Convento de San Francisco } \\
\hline & & & \multirow{2}{*}{\multicolumn{2}{|c|}{$\begin{array}{l}\text { Generalife. Pórtico Norte } \\
\text { Peinador de la Reina (P.B) }\end{array}$}} & \multirow{2}{*}{\multicolumn{2}{|c|}{$\begin{array}{l}\text { Partal. Torre de las Damas } \\
\text { Generalife. Salón norte }\end{array}$}} & \multicolumn{2}{|c|}{ Puerta de las Granadas } & \multicolumn{2}{|c|}{ Puerta de los Carros } \\
\hline & & & & & & & Habitaciones & de Carlos V & $\ldots$ & \\
\hline & & & \multicolumn{2}{|l|}{$\ldots$} & \multicolumn{2}{|l|}{$\ldots$} & \multicolumn{2}{|c|}{ Peinador de la Reina (P.A). } & & \\
\hline \multicolumn{3}{|c|}{ Obras resto ciudad de Granada } & \multicolumn{2}{|l|}{ Cuarto Real } & \multicolumn{2}{|c|}{ Corral del Carbón } & \multicolumn{2}{|c|}{ Claustro Santa Paula } & \multicolumn{2}{|c|}{ Catedral / Capilla Real } \\
\hline & & & \multicolumn{2}{|c|}{ Casa de los Girones } & \multicolumn{2}{|c|}{ Alcázar Genil } & \multicolumn{2}{|c|}{ Puerta de San Lorenzo } & San Jerónimo & \\
\hline & & & Casa de Chap & & Casa de Chap & iz (reforma) & Aljibe de San & Nicolás & Santa Isabel la & Real \\
\hline & & & Aljibe del Re & & Aljibe de las & Tomasas & Aljibe del Zen & iete & San Matias & \\
\hline & & & Aljibe de Tril & & Aljibe de Sar & Miguel & Aljibe Peso de & la Harina & Hospital Real & \\
\hline & & & $\ldots$ & & $\ldots$ & & $\ldots$ & & San Juan de D & ios, ... \\
\hline
\end{tabular}

Figura 6. Tabla de métricas históricas de Granada. 
utilización de una referencia distinta que suponemos corresponde con la antigua vara de Toledo (Roldán 2018a). Por su parte el Palacio de Comares, el Patio de los Leones y buena parte de la Granada nazarí fueron construidos con una métrica de $182 \mathrm{~cm}$. Sin embargo las obras más antiguas de este reinado (Baños reales de la Alhambra, Palacio del Partal, Generalife, Cuarto Real,...) presentan distinto módulo, uno mayor de 208 cm (Roldán 2017).

El chequeo no exhaustivo de numerosos elementos arquitectónicos del caserío granadino y su confrontación con los distintos patrones de las medidas locales (Fig. 7) está ofreciendo reveladores resultados sobre obras consideradas tradicionalmente como moriscas, mudéjares, neo-alhambreñas o simplemente modernas, y que presentan métrica del segundo o primer periodo nazarí (Roldán 2018b).

Podría ser el caso que nos ocupa, el artesonado o armadura apeinazada en forma de artesa que cubre el Salón de Caballeros XXIV de la Madraza de Granada. Un magnífico ejemplar ochavado de limas moamares con decoración de lazo de ocho, considerables dimensiones y atado con dos pares de tirantes, aunque similar en técnica y diseño a otras obras de carpintería de lo blanco que podemos encontrar en esta misma ciudad (Gómez-Moreno et al. 2001; López Pertíñez 2006).

\section{LAS MEDIDAS DE LA MADRAZA}

Se ha realizado un modelo fotogramétrico de la armadura del que se han obtenido varias vistas diédricas generales como las presentadas en la Figura 5, así como de detalle de varios de sus elementos más representativos (Fig. 8).

Igualmente se han registrado fotogramétricamente el alfarje -o forjado de madera del piso del salón- y el techo del oratorio. Para facilitar la interpretación constructiva del conjunto se han superpuesto las fuentes planimétricas y las ortofotos generadas en su posición relativa (Fig. 9).

Con estas fuentes gráficas, y aplicando la regla armónica de composición con lados y diagonales del mismo cuadrado, se han descifrado las medidas $\mathrm{y}$ proporciones de distintos elementos constructivos que componen el actual edificio de la madraza, y cuyos resultados exponemos a continuación.

El canónico diseño de estas estructuras modulares (Fig. 10) revela que todos los pares de la armadura del
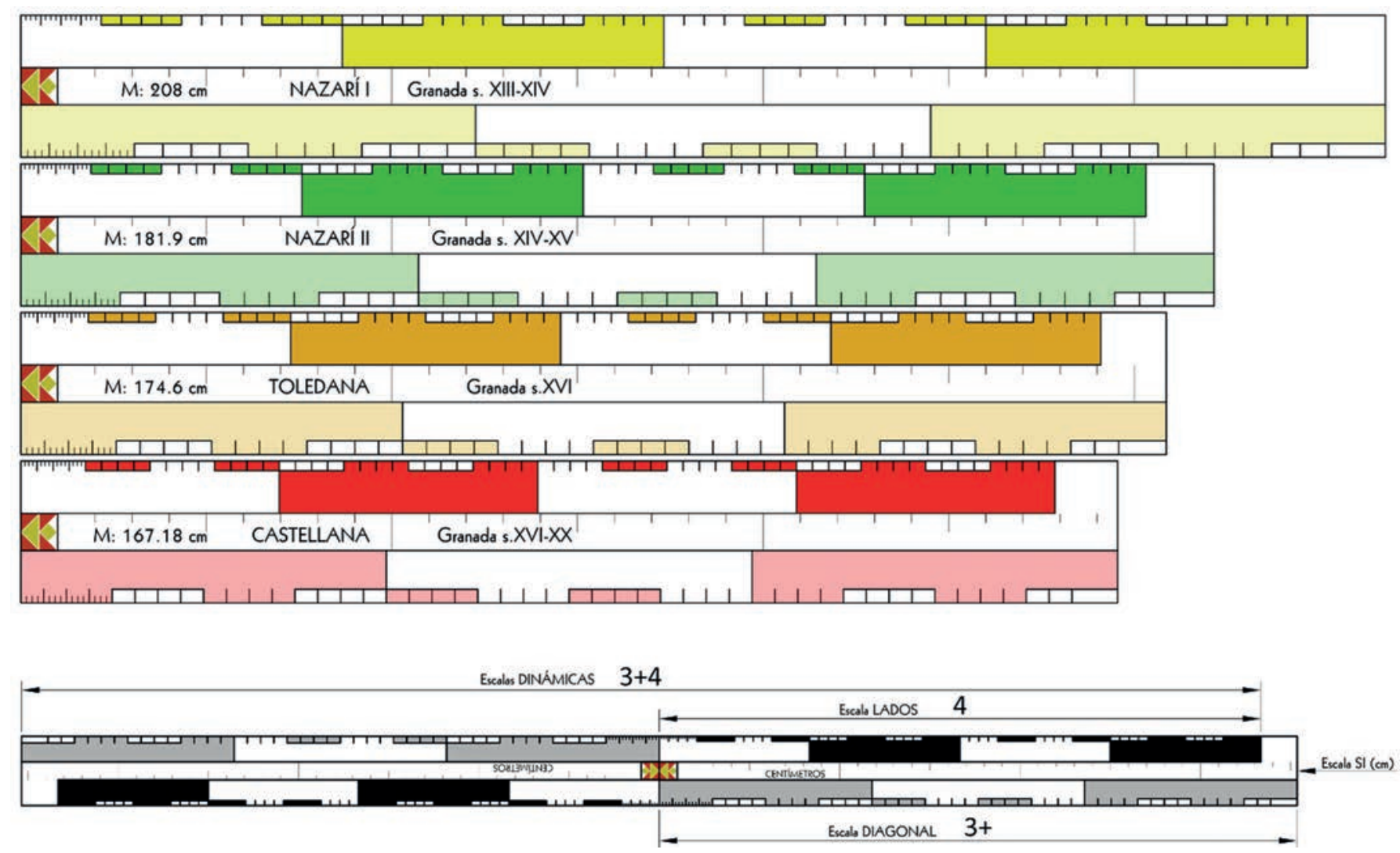

Figura 7. Reglas de Granada. 

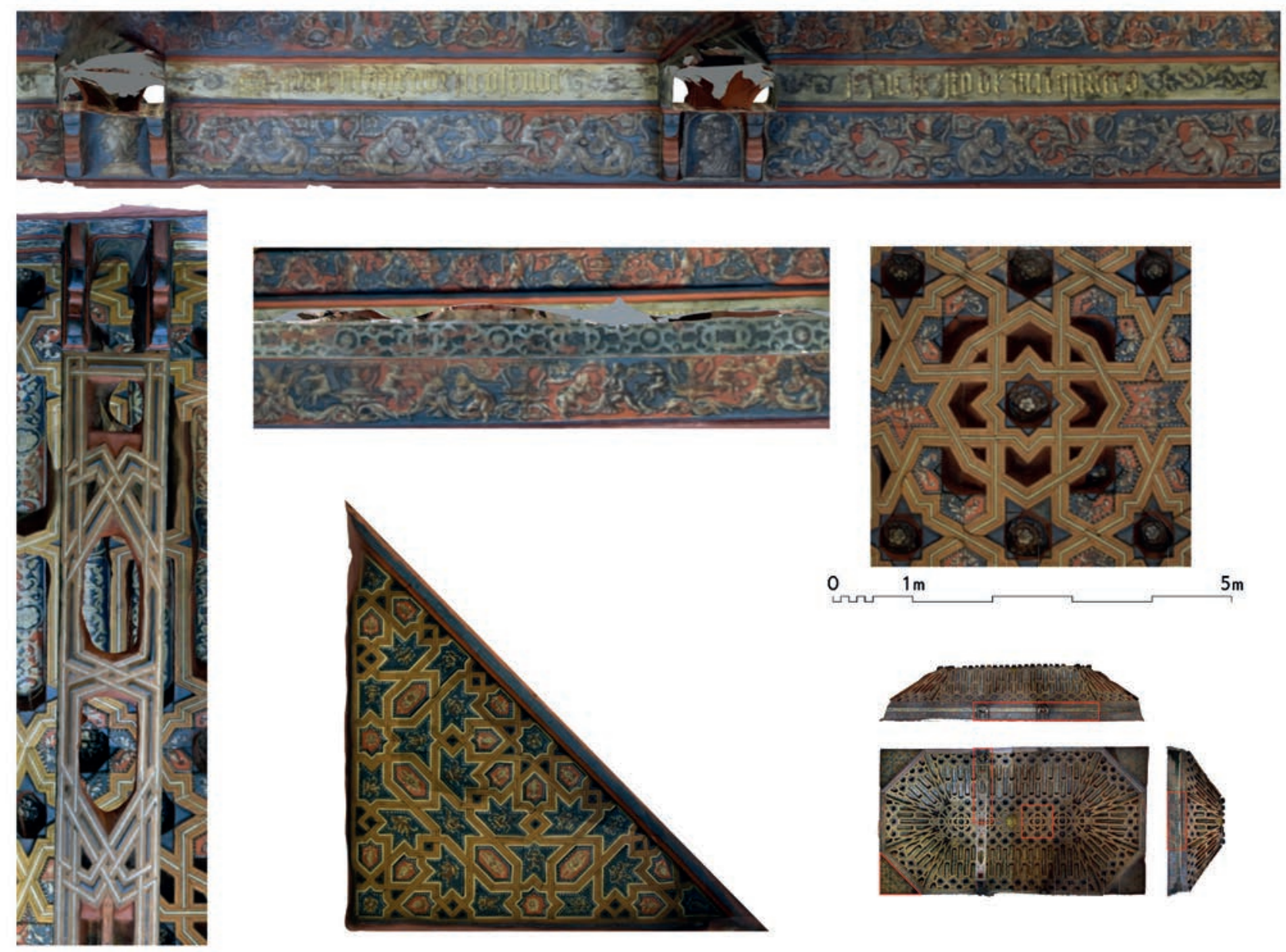

Figura 8. Ortofotos de distintos detalles de la armadura.

Salón de Caballeros XXIV equidistan $32,15 \mathrm{~cm}$, lo que coincide con el valor de 1 cuarta diagonal de métrica Nazarí II, es decir, un octavo de $181,88 \mathrm{~cm}$ por la raíz cuadrada de dos. Sobre una cuadrícula con este módulo se desarrolla la estructura y la decoración de lazo del almizate, sobre seis calles longitudinales y veinticuatro transversales hasta alcanzar los 3 codos diagonales de ancho por 3 brazas diagonales de largo en proporción 1:4 (192,91 x 771,65 cm). Cada uno de los cinco motivos octogonales que componen su labor de lazo mide 1 vara diagonal $(128,61 \mathrm{~cm})$.

Como la proyección de los faldones es de otra braza diagonal $(257,22 \mathrm{~cm})$, el largo total de la armadura apeinazada alcanza las 5 brazas diagonales $(1286,09$ $\mathrm{cm})$ y el ancho queda definido con 11 codos diagonales $(707,35 \mathrm{~cm})$. El resto de espacio hasta completar la dimensión total del actual salón se dedica al vuelo del arrocabe sobre el que se apoya.

Por un lado se hace la observación de que el ancho del almizate no coincide con un tercio del espacio a cubrir, que es la regla que indica López de Arenas (Nuere 1985: 60) en su tratado para este tipo de armaduras. En este caso serían 3/11 (0,27 periódico).

Por otra parte la altura de la armadura coincide con 1 braza, por lo que la pendiente o hipotenusa de la cubierta es, según el teorema de Pitágoras, la raíz cuadrada de tres. Como en otras ocasiones encontramos mediante la regla de lados y diagonales sencillas aproximaciones enteras a valores reales notables, como es el también irracional $\sqrt{ } 3 \approx 1,732$. Aquí se puede establecer que el desarrollo de cada faldón (la hipotenusa) es 7 codos $(318,29 \mathrm{~cm})$ cometiendo un error del 1\%.

Esta inclinación o pendiente supone un ángulo de $35^{\circ}$, algo menor al cartabón de cinco $\left(36^{\circ}\right)$ que solían emplear los alarifes castellanos.

El estudio en detalle (Fig. 11) del diseño de lazo de la armadura revela que el ancho de calle o espacio entre pares tampoco cumpliría la regla de calle y cuerda (Nuere 1985: 85). En vez de dos tercios de la separación entre ejes de pares para el ancho de calle, y un tercio 

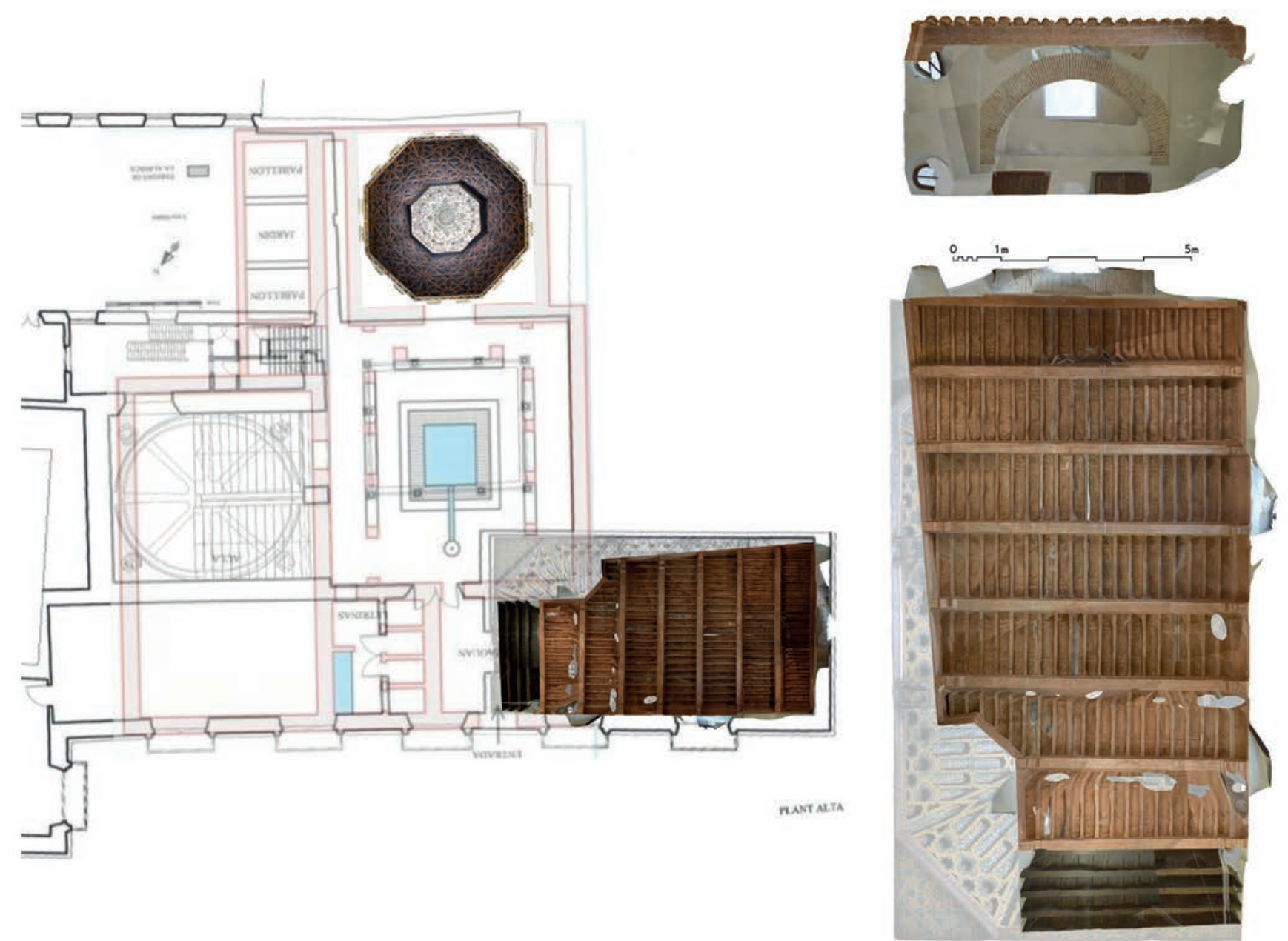

Figura 9. Ortofotos del alfarje del piso del salón sobre proyección de la armadura. Superposición con los planos de planta de las Figuras 3 y 4.
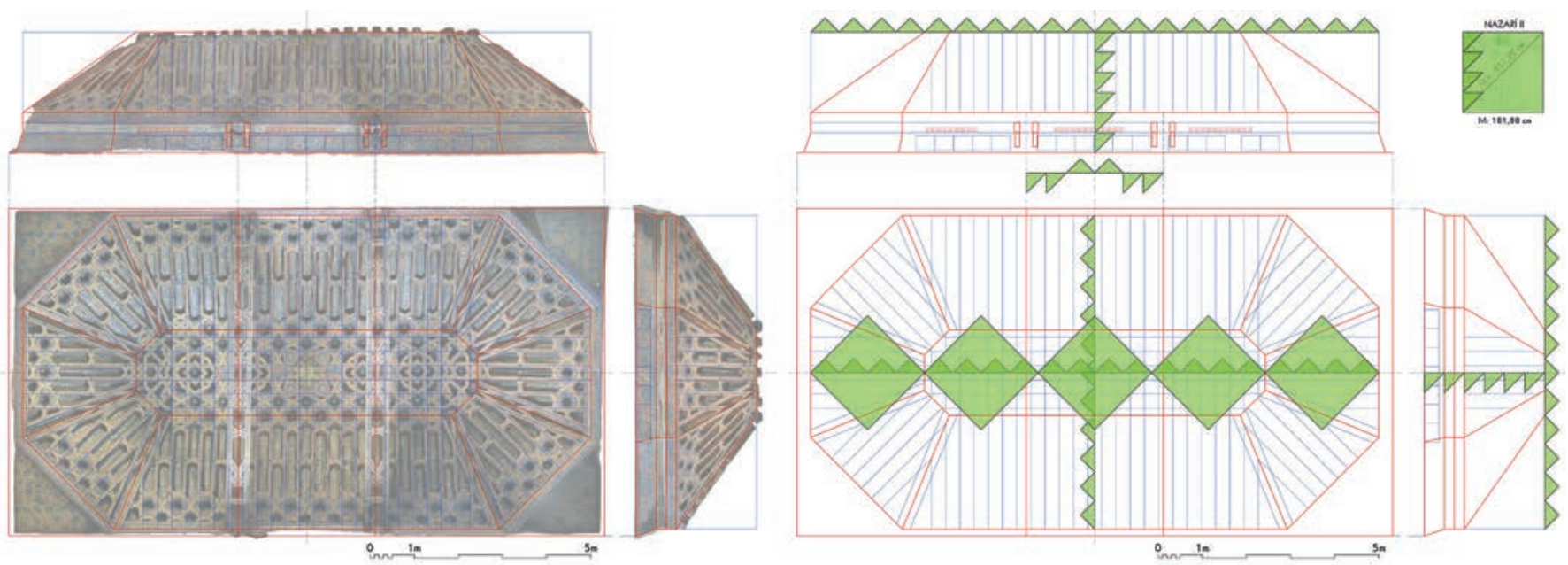

Figura 10. Modulación general de la armadura. 

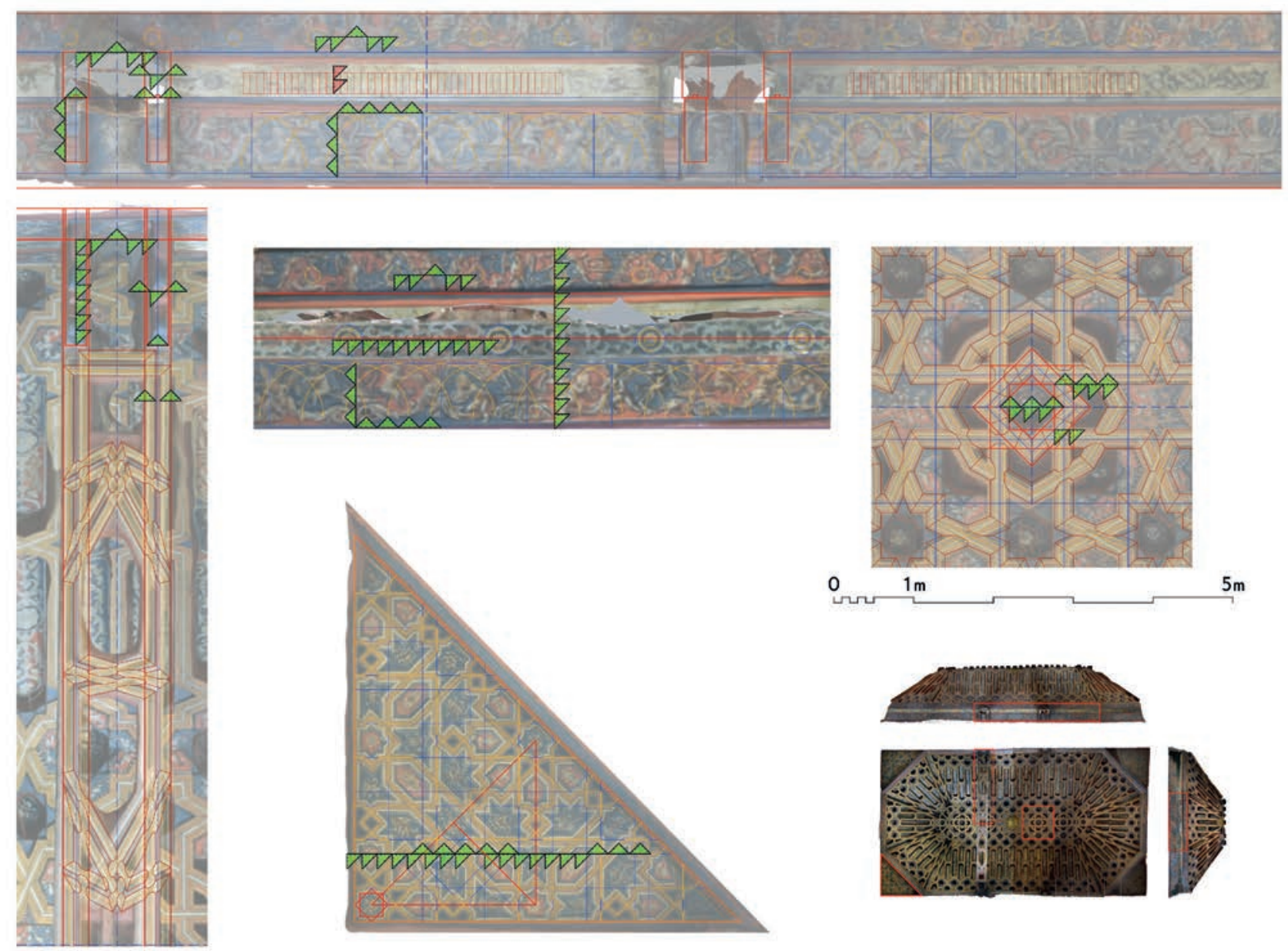

Figura 11. Modulación de detalles.

para el ancho del par, este modelo adopta una calle algo más ancha, concretamente de 1 cuarta $(22,74 \mathrm{~cm})$ con la que se generan sus sinos octogonales. Por lo tanto el ancho de par queda definido por $\sqrt{2}-1$ cuartas, lo que prácticamente son 5 dedos $(9,47 \mathrm{~cm})$.

Como en otras ocasiones (Roldán 2014a: 295-297, 318) encontramos ejemplos de armaduras de lazo granadinas que no responden a las recetas dadas en el tratado del alarife sevillano Diego López de Arenas al menos un siglo después de la construcción de este ejemplar, y que se refieren a ciertos casos simplificados de diseño. De hecho la regla de 1/3 del ancho de la estancia para el almizate, la regla de calle y cuerda, y la regla de establecer la pendiente o cartabón de la armadura en base a divisiones enteras del círculo, implican grandes limitaciones que en principio no son necesarias para diseñar una armadura legítima de lazo. Se puede emplear cualquier proporción de almizate, cualquier proporción de calle y cuerda, y cualquier inclinación de faldones sin producir desajustes.
Además la regla "Arenas" de 1/3 obliga a tener que fabricar escuadrías específicas (no comerciales) para todas sus maderas, sin considerar por otra parte que por el vuelo del arrocabe la armadura vista siempre debe ser algo más pequeña que el ámbito a cubrir.

Aquí el arrocabe contiene tanto los tirantes como las ochavas planas de las esquinas. Su altura es de 2 codos distribuidos en un friso superior continuo de 1 cuarta, otro intermedio que coincide con la altura de los tirantes y también de 1 cuarta, y el inferior de 1 codo donde se localizan las ocho zapatas de los pares de tirantes.

Los ejes de los dos tirantes dobles equidistan $\sqrt{ } 2+2$ varas -una diagonal más dos lados de vara cuadrada-, lo que representa $310,49 \mathrm{~cm}$. Cada tirante dispone de dos pares separados $\sqrt{ } 2+4$ palmos a eje $(48,61 \mathrm{~cm})$. Cada par tiene un ancho de $2 \cdot \sqrt{ } 2+4$ dedos $(13 \mathrm{~cm})$, y en cada uno se desarrolla el doble lazo de la decoración con 2 dedos diagonales de ancho o cuerda $(5,36 \mathrm{~cm})$. 
Los triángulos de las ochavas se solucionan con un artesonado plano ataujerado al nivel inferior del alicer. Presentan también labor de lazo de ocho, pero en este caso el diseño es dinámico con calles de sinos de 9 dedos a eje $(17 \mathrm{~cm})$, calles dobles de 9 dedos diagonales $(24 \mathrm{~cm})$, y 2 dedos diagonales de ancho de cuerda $(5,36 \mathrm{~cm})$.

Es significativo que las pinturas platerescas que decoran el artesonado, y en concreto las del alicer y los tirantes, también responden a modulaciones de métrica Nazarí II. Así el motivo decorativo de la franja superior del alicer presenta divisiones cada $41 \mathrm{~cm}$, que correspondería con $\sqrt{2}+4$ palmos. El inferior presenta similar decoración en patrones de 1 pie diagonal de ancho por 1 cuarta diagonal de alto, que recuerda en proporción y distribución el alicer de arcos entrelazados del Cuarto Real. En los tirantes se distribuyen motivos circulares de 2 palmos de diámetro cada 10 palmos.

Distinto resultado se obtiene en el análisis de las medidas del épico texto que ocupa la franja intermedia del alicer. Sus dorados caracteres latinos se ajustan a una cuadrícula de 6 dedos de alto por 2 de ancho de métrica Castellana, por lo que sería el único elemento de la armadura ejecutado con esa referencia de medida.

Con estos valores teóricos se ha reconstruido el diseño del lazo y decorativo de la armadura, lo que permite comparar el modelo teórico con el modelo fotogramétrico (Fig. 12), así como generar el desarrollo de sus faldones a partir de la montea de su geometría con las medidas que pudo utilizar su autor (Fig. 13).

El resto del salón y del edificio, excepto el oratorio de métrica Nazarí II, aparecen ejecutados con medida Castellana. Así se puede confirmar en el alfarje o forjado del salón, compuesto por vigas madre separadas 1 vara $(167,18 \mathrm{~cm})$ sobre las que descansan viguetas separadas 18 dedos $(31,35 \mathrm{~cm})$, así como en el muro testero en planta baja, con un arco de ladrillo de medio punto, 2 brazas de diámetro y rosca de 2 pies (Fig. 14).

Se observa el descuadre de la medianera y alfarje de la sala en planta baja, su estrechamiento en la zona de patio, y el hecho de que el salón superior y su armadura superan estas irregularidades e invaden tanto el lindero como el patio. Además el salón resulta más largo que el alfarje, por lo que la parte inicial apoya en otro forjado de viguetas simples que se extiende por el actual zaguán.

Se acompaña una tabla (Fig. 15) con los principales valores teóricos de las medidas descifradas, con indicación del número entero de diagonales y lados de la composición, la fracción o unidad antropométrica utilizada, y el valor decimal en centímetros. Destaca el hecho de que las dimensiones generales de la artesa se definan mediante la medida diagonal, y las de los tirantes con combinaciones dinámicas. Otros elementos y la obra castellana se limitan a fracciones ordinarias de la correspondiente referencia.
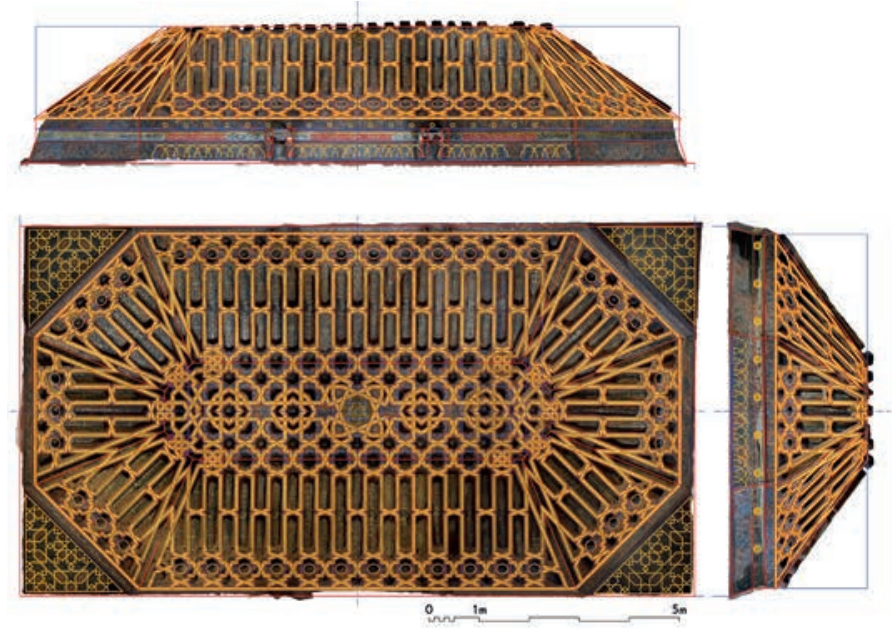

Figura 12. Modulación y superposición del modelo teórico sobre el real.
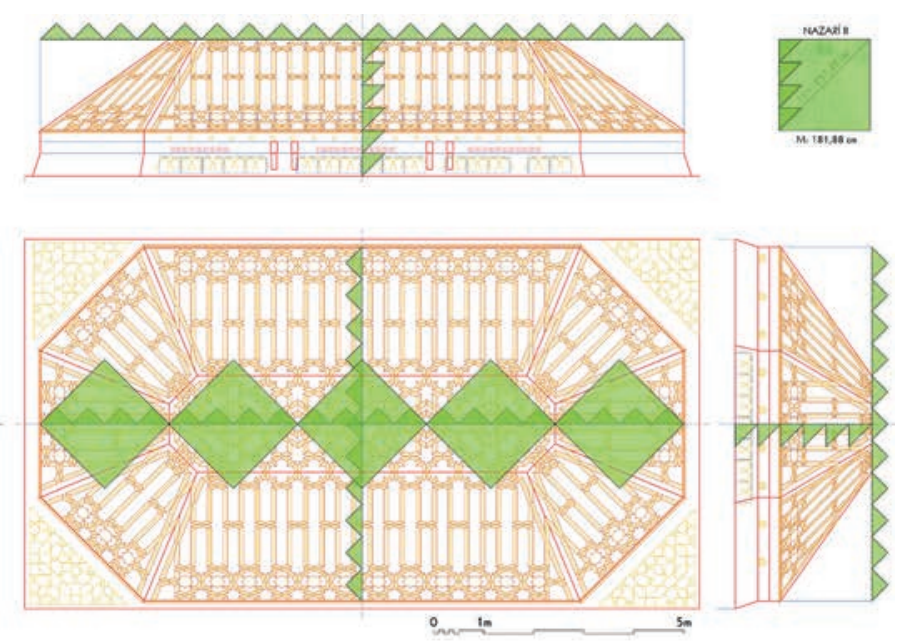


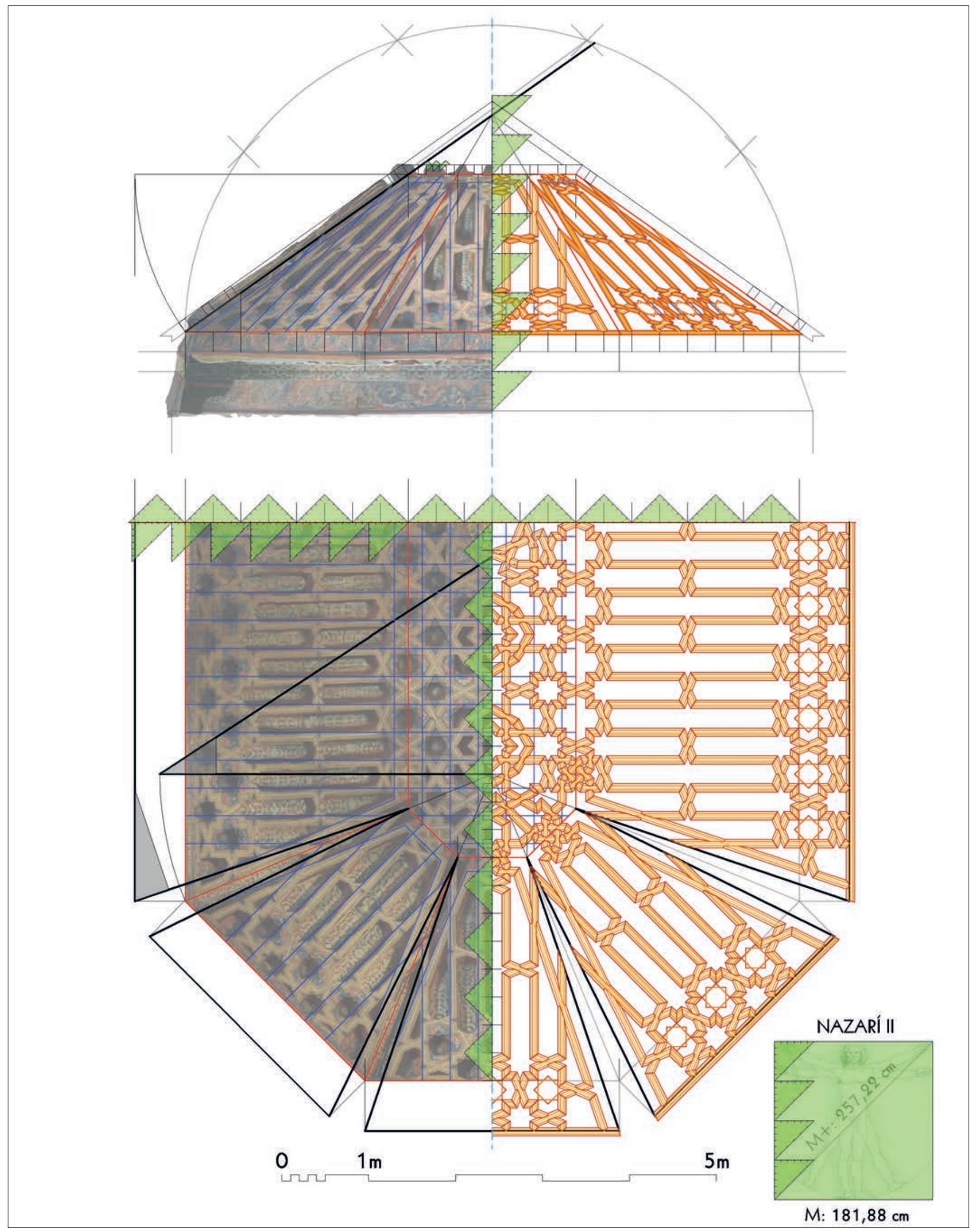

Figura 13. Trazas y desarrollo de la armadura. 

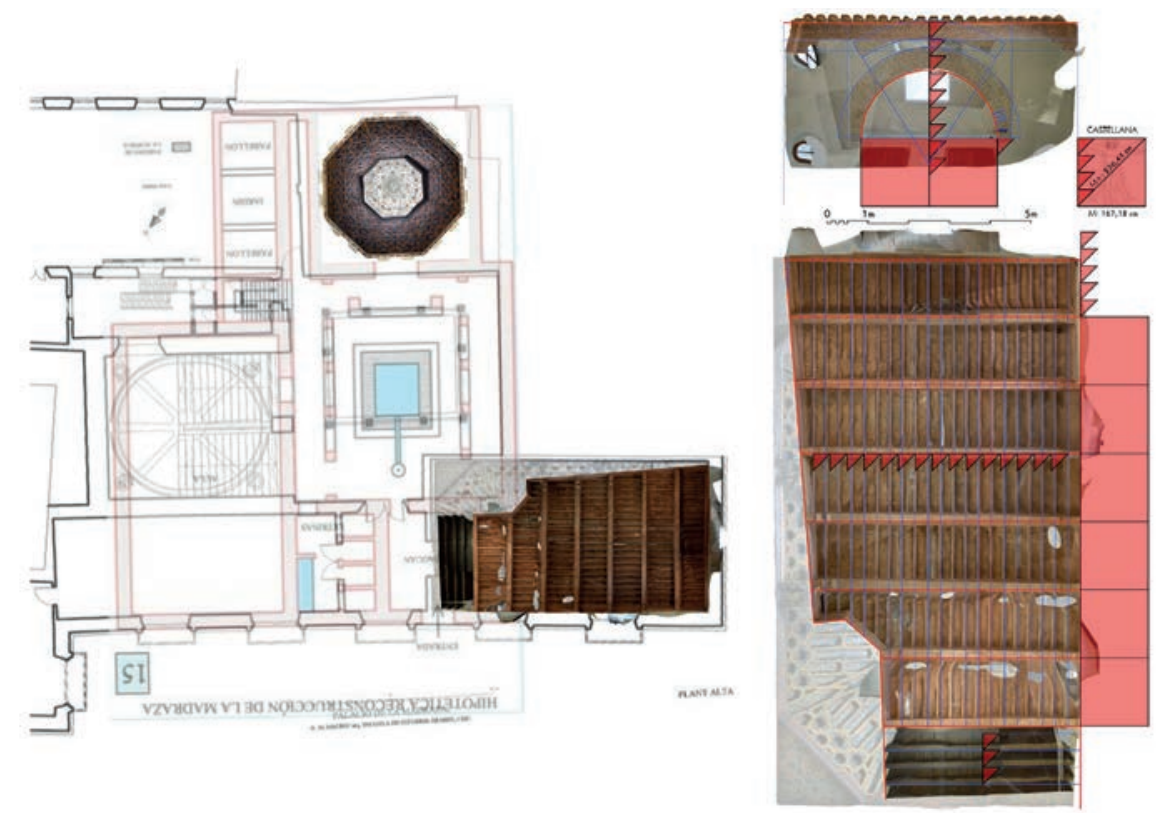

Figura 14. Modulación del alfarje y testero.

\begin{tabular}{|c|c|c|c|c|c|c|}
\hline id & Denominación & \begin{tabular}{|l|} 
Diagonales \\
\end{tabular} & Lados & Fracción & Antrou & $\mathrm{cm}$ \\
\hline ARMADURA & Módulo NAZARÍ II & & 1 & 1 & вRAZA & 181,88 \\
\hline \multirow[t]{16}{*}{ Artesa } & Intereje pares & 1 & & $1 / 8$ & CUARTA & 32,15 \\
\hline & Pares largo almizate & 24 & & $1 / 8$ & CUARTA & 771,65 \\
\hline & Largo almizate & 3 & & 1 & BRAZA & 771,65 \\
\hline & Pares ancho almizate & 6 & & $1 / 8$ & CUARTA & 192,91 \\
\hline & Ancho almizate & 3 & & $1 / 4$ & $c 000$ & 192,91 \\
\hline & Proyección faldones & 1 & & 1 & BRAZA & 257,22 \\
\hline & Largo artesa & 5 & & 1 & BRAZA & 1286,09 \\
\hline & Ancho artesa & 11 & & $1 / 4$ & coos & 707,35 \\
\hline & Alto artesa & & 1 & 1 & BRAZA & 181,88 \\
\hline & Alto arrocabe & & 2 & $1 / 4$ & $c 000$ & 90,94 \\
\hline & Alto total armadura & & 6 & $1 / 4$ & cooo & 272,82 \\
\hline & Ancho aprox. faldones & & 7 & $1 / 4$ & cooo & 318,29 \\
\hline & Ancho calle & & 1 & $1 / 8$ & CUARTA & 22,74 \\
\hline & Ancho $2 / 3$ (Arenas) & 2 & & $1 / 24$ & PALMO & 21,43 \\
\hline & Ancho par & 1 & -1 & $1 / 8$ & CUARTA & 9,42 \\
\hline & Ancho aprox. par & & 5 & $1 / 96$ & DEDO & 9,47 \\
\hline \multirow[t]{4}{*}{ Alicer } & Alto total & & 2 & $1 / 4$ & $c 000$ & 90,94 \\
\hline & Alto friso superior & & 1 & $1 / 8$ & CUARTA & 22,74 \\
\hline & Alto friso intermedio & & 1 & $1 / 8$ & CUARTA & 22,74 \\
\hline & Alto friso inferior & & 2 & $1 / 8$ & CUARTA & 45,47 \\
\hline \multirow[t]{9}{*}{ Tirantes } & Intereje tirantes & 1 & 2 & $1 / 2$ & vara & 310,49 \\
\hline & Intereje pares tirantes & 1 & 5 & $1 / 24$ & PALMO & 48,61 \\
\hline & Ancho pares & 2 & 4 & $1 / 96$ & DEDO & 12,94 \\
\hline & Ancho lazo o cuerda & 2 & & $1 / 96$ & DEDO & 5,36 \\
\hline & Diámetro decoración & & 2 & $1 / 24$ & PALMO & 15,16 \\
\hline & Separación decoración & & 10 & $1 / 24$ & PALMO & 75,78 \\
\hline & Ancho decoracion sup. & 1 & 4 & $1 / 24$ & PALMO & 41,03 \\
\hline & Ancho decoracion inf. & 1 & & $1 / 6$ & PIE & 42,87 \\
\hline & Alto decoracion inf. & 1 & & $1 / 8$ & CUARTA & 32,15 \\
\hline \multirow[t]{3}{*}{ Ochava } & Calle sino & & 9 & $1 / 96$ & DEDo & 17,05 \\
\hline & Calle doble & 9 & & $1 / 96$ & DEDO & 24,11 \\
\hline & Cuerda & 2 & & $1 / 96$ & DEDO & 5,36 \\
\hline Castellana & Módulo Castellano & & 1 & 1 & BRAZA & 167,18 \\
\hline \multirow[t]{2}{*}{ Epigrafia alicer } & Altura texto & & 6 & $1 / 96$ & DEDO & 10,45 \\
\hline & Ancho letra & & 2 & $1 / 96$ & oEoo & 3,48 \\
\hline \multirow[t]{4}{*}{ Alfarje } & Sep. Vigas madre & & 1 & 1 & BRAZA & 167,18 \\
\hline & Sep. Viguetas & & 18 & $1 / 96$ & DEDO & 31,35 \\
\hline & Diámetro arco testero & & 2 & 1 & BRAZA & 334,36 \\
\hline & Rosca arco & & 2 & $1 / 6$ & PIE] & 55,73 \\
\hline
\end{tabular}

Figura 15. Tabla de medidas teóricas.

\section{LA MADRAZA YUSUFIYYA}

Tipológicamente, todos los autores señalan el ascendiente de la madraza Yusufiyya, tanto funcional como arquitectónico en las madrazas norteafricanas. Estas tenían el mismo organigrama docente y residencial que los grandes prototipos orientales, pero eran más reducidas en tamaño y de organización más sencilla. Los ejemplares mariníes, y por ende el granadino, eran edificios en torno a un moderado patio central, rodeado por una galería, un vestíbulo de entrada y el oratorio en uno de los lados, normalmente opuesto a la entrada y una o dos salas para la docencia, en planta baja; en la planta superior se disponía una estrecha galería con su corredor en torno al patio, para permitir el acceso a las celdas de los estudiantes. Por último también debía de contar con una biblioteca (Malpica y Mattei 2015).

La configuración de la madraza Yusufiyya debía de seguir esta estructura y hasta épocas cercanas solo había sido conocida a través de unas pocas fuentes escritas y las propias inscripciones contenidas en el edificio. En la actualidad ha ido tomando cuerpo gracias a la intervención arqueológica llevada a cabo durante 2006-2007. Estudio que ha requerido una prospección geofísica previa a la excavación arqueológica y cuyos resultados han sido recogidos en la obra "La Madraza de Yusuf I y la ciudad de Granada. Análisis a partir de la arqueología", de los cuales pasamos a citar de forma sintetizada aquellos que nos 
han ayudado a acercarnos a la posible distribución original del edificio.

Era un edificio de pequeñas dimensiones en cuya entrada, dispuesta en la actualidad en otra posición, tenía una inscripción coránica con una leyenda y encima dos losas de mármol blanco primorosamente labradas, imitando dos ventanas cada una con pasajes de dichas inscripciones. La entrada daba paso a un zaguán, al cual se accedía al pasar la puerta de entrada. Tras este se pasaba al patio a través de una puerta que no estaba enfrentada a la primera, manteniendo así una cierta intimidad. El patio, que a grandes líneas coincidía con la superficie que ocupa el actual, contenía en su centro una pequeña alberca.

Desde el patio, opuesto a su entrada, se accedía al oratorio. La intervención arqueológica ha podido constatar un dato que aún no estaba comprobado. Los cuatro muros perimetrales son con seguridad pertenecientes a la edificación de la madraza y la ubicación del mihrab, que debió de ser más profundo, conserva su posición original.

Aunque el conjunto patio y oratorio era perfectamente simétrico, la madraza poseía una planimetría asimétrica. Efectivamente, el lado occidental del patio estaba delimitado por un potente muro de mampostería encintada lindando con propiedades privadas, mientras que al lado oriental se ha considerado, siguiendo los datos de las fuentes modernas, que se extendía una crujía a la cual se accedía a través del patio; esta podría ser el Aula de enseñanza.

La planta superior que debió de existir -como así lo atestiguan la existencia de dos escaleras aunque la mayoría de las fuentes solo nos hablan de una- es donde debían de localizarse los dormitorios de los alumnos separados por tabiques, como es habitual en otras madrazas conservadas en ciudades islámicas, y en nuestro caso en el lado oriental justo por encima del Aula.

También gracias a los trabajos arqueológicos se ha confirmado la presencia de un pequeño jardín citado en las fuentes. Este se hallaba al costado oriental del oratorio, y los muros de mampostería encintada que lo delimitaban nos hacen pensar que estaba bordeado por dos pequeños pabellones. Por último en un edificio de estas características era obligatoria la existencia de unas letrinas. Ubicadas en la reconstrucción junto al zaguán, aunque su constatación arqueológica no ha podido hacerse al quedar esta zona fuera del área excavada.
Todos estos datos arqueológicos han permitido llevar a cabo una reconstrucción hipotética de lo que pudo ser la distribución de la universidad árabe en su planta baja (Fig. 4), donde se han recogido datos fehacientes de parte del sistema murario original del edificio gracias a los sondeos, junto con otros que se mueven más en el campo de las conjeturas al no haber podido excavar para verificarlos. En referencia a estos últimos se encontraría la ubicación dada en planimetría de la sala o Aula de enseñanza, cuyas dimensiones y situación espacial en el edificio no han podido ser confirmadas. No obstante la certeza de su existencia es ratificada por algunas de las fuentes consultadas como más adelante veremos.

\section{LAS CASAS DEL CABILDO VIEJO (1500- 1858)}

En el año 1500 se inicia el segundo periodo histórico del Palacio de la Madraza pasándose a denominarse como "Casa del Cabildo", es decir la sede capitular del ayuntamiento o concejo granadino. A partir de este momento el edificio comienza a sufrir una serie de transformaciones para adaptarse al nuevo uso y a las nuevas tradiciones culturales que podemos dividir en dos etapas: en primer lugar los años iniciales del siglo XVI que afectaron principalmente a la crujía de la fachada; $y$ en segundo lugar la década de 1720 cuyas profundas reformas son las que nos han proporcionado en gran medida la imagen actual del inmueble.

\section{Siglo XVI-XVII}

Las primeras alteraciones consistieron pues, más que en la transformación del edificio islámico, en la adición de solares colindantes para aumentar la funcionalidad de la sede concejil. Un primer paso en este sentido se llevó a cabo en diciembre del mismo año 1500, cuando se compró al vecino Diego Hernández una casa con objeto de ampliar la madraza. Dicha casa pudo haber pertenecido a los bienes habices (Lafuente 1986: 220) previamente a la conquista, pero sea como fuere después de la escritura de traspaso se precedió a integrar ambos inmuebles en uno solo, lo que pudo tener lugar durante las dos primeras décadas del siglo XVI. La mayoría de las fuentes editadas tienden en coincidir en que este cuerpo añadido se reconstruyó ex novo y en él se creó la sala alta del cabildo, Salón de Caballeros 
XXIV o sala capitular de invierno, junto con la armadura que la cubre y su correspondiente piso inferior. La realidad es que la secuencia de las actuaciones que se llevaron a cabo en esta vivienda es difícil de interpretar, pues la desaparición de los libros capitulares desde 1502 a 1512 genera lagunas que impiden seguir el ritmo de las obras.

Los trabajos debieron de comenzar en 1501 con la compra de materiales a cargo del obrero de la ciudad Gonzalo Delgadillo tras analizar el mal estado en que se encontraba el edificio:

Fablaron en que la casa del Cabildo está a lo baxo de los çimientos malo y desgouernado de cuya causa las pieças del yeso se cahen e se daña la casa, e para lo prouer e remediar mandaron a Gonçalo Delgadillo, obrero, que luego conpre yeso e los otros materiales que fueren menester e maestros para que luego se repare y escriua lo que asy se gastare en su libro de cuenta, e se la ha resçibydo de los maravedís de su cargo (Moreno 2005: 451).

A partir también de 1501 comenzamos a tener noticias documentales que nos indicarían cómo la casa contigua adquirida fue allanada o acondicionada para dar mayor ensanche de la sede capitular y cómo la sala de audiencia se construyó junto a la casa del cabildo y frente al aljibe de la Capilla Real. Las actas capitulares del año 1502 citan el derribo de la vivienda adquirida: "Mandaron que Vitoria venda en el almoneda la madera que se ha sacado de las casas que se derribaron junto con las casas del cabildo" (Moreno 2005: 530) y la adjudicación de las obras de la sala de la audiencia por 70.000 maravedís al albañil Hernando de Sepúlveda en febrero de 1502.

En este día el señor corregidor e Alonso Vélez de Mendoça e Luis de Valdiuia, regidores, e Françisco de Morales e Sancho Méndez, jurados, mandaron asentar cómo Fernando de Sepúlveda, alvañí, avía abaxado la obra del Avdiençia en setenta mil maravedís por dos castellanos de prometido, que haciendo la baxa antel escriuano como lo avía hecho ante ellos se asyente la postura e se le dé el prometido (ibíd.: 575).

Otras actuaciones de ese mismo año consistieron "en limpiar la casylla questá junto con el Cabildo e la çierre e la abra por la casa del Cabildo" (ibíd.: 592) lo cual nos puede inducir a pensar que las viviendas pudieron no derribarse en su totalidad. También se habilitó un espacio para aposentamiento del señor corregidor.

De cualquier forma no será hasta el año 1512 cuando podamos seguir el rastro de la evolución constructiva del conjunto, donde se cita librar al albañil Francisco Xymena dos mil maravedís "para conplymyento a los çinquenta y nueve myll maravedís que se les avyan de dar por acabar la obra de la casa del cabildo" (Guerrero 2007: 110), aunque se desconoce si las obras seguían siendo en la casa añadida ni a qué sala en concreto afectaban.

Posteriormente en el año 1513 se le paga al pintor Francisco Hernández, en dos cargos de 4 ducados y 3.400 maravedíes respectivamente, por "la pintura de la sala del cabildo" (ibíd.: 206). Pintura que debía referirse a la pintura de gusto plateresco de la armadura de la sala alta. Terminada la pintura en 1515 se libran 12.200 maravedís al carpintero Bernabé de Burgos por los escaños que "hyzo para la sala alta del cabildo" (ibíd: 696). En 1516 se manda hacer unos lienzos para la ventana de la sala alta del cabildo (García 1988: 361). Y finalmente las salas alta y baja serían enladrilladas por el albañil Gines en el año 1521 (Jiménez 1987: 176).

En definitiva este relato de actuaciones nos da a entender que durante estos primeros años del siglo las obras se debieron de centrar en la crujía de fachada, constituyendo lo que debía de ser la sala alta y la sala de audiencia en la planta inferior. En paralelo a estas obras, entre los años 1514 y 1518 se van a ir produciendo otras cuya ubicación no está tan clara en la denominada "cuadra baja del Cabildo", así como la habilitación de viviendas y portería. El término "cuadra" puede referirse tanto a una estancia en concreto como a toda la planta baja de la antigua madraza, si bien cabe suponer-debido a la costumbre de disponer de salas capitulares de invierno y verano, ubicadas las últimas en el piso inferior más fresco- que aquella acepción identificara a la sala baja del cabildo. En 1515 "acordaron y mandaron que se ladrylle la quadra baxa de la casa del cabyldo, de ladryllo mazary con sus azulejos e que vaya muy byen hecho y mandáronme a my que tuviese cargo de lo hazer" (Guerrero 2007: 736). En 1517 se libraron por un lado tres mil maravedís al carpintero Castillo "por los escaños que hizo para la cuadra baja del cabildo" (García 1988: 388), y otros dos mil maravedís a un obrero para la obra de la capilla que se está haciendo en dicha estancia. 
Si resulta casi imposible saber con esta parquedad documental a que espacio se refiere la documentación citada como "cuadra baja del Cabildo", documentos posteriores fechados en el siglo XVII, como veremos más adelante, aclaran la cuestión al identificarse dicha sala con el espacio ochavado que hoy conocemos como oratorio islámico, dentro del cual debió existir un pequeño espacio sacro, capilla o altar cristiano.

Con ello la madraza contaría desde una fecha temprana con los elementos sustanciales de un consistorio quinientista: la sala capitular de invierno o alta, la sala de audiencia - cuyos datos históricos no nos revelan con certeza su ubicación exacta- y la sala capitular baja o de verano en el actual oratorio, donde además se debió incluir una pequeña capilla. A pesar de ello la imagen que debieron de tener las Casas Consistoriales del Consejo de Granada durante el siglo XVI debía de ser de un edificio desordenado fruto de una amalgama de edificaciones en las que la antigua madraza Yusufiyya conviviría con la crujía nueva de las casas aledañas y con unos espacios de menor significación. Esta mezcolanza daría al conjunto un aspecto pintoresco pero también contribuiría a su progresiva depauperación. Se comprende pues que el edificio fuese objeto de reformas o remodelaciones una vez concluida en lo substancial la adaptación del conjunto a las normas y usos de los municipios castellanos.

El cronista barroco Henríquez de Jorquera, guía imprescindible para documentar las intervenciones más sonadas, hace mención a importantes reformas acaecidas el año 1626:

Granada mandó hacer estas Casas del Cabildo, siendo corregidor en ellas don Rodrigo Pacheco, marqués de Cerralbo. Año de 1554. Y Granada mandó reedificar estas Casas del Cabildo siendo corregidor don Luis Lasso de la Vega, caballero del hábito de Calatrava, mayordomo del serenísimo infante don Fernando. Año 1626 (Cruz y Gómez-Moreno 2007: 59).

Por desgracia esta cita literaria no aclara ni el alcance ni la naturaleza de aquellas reedificaciones. También obliga a plantearse que si en la inscripción se mencionaba que las casas del cabildo habían sido hechas en 1554, alguna obra importante debería haberse realizado entonces para que quedara constancia expresa, seguramente en otra placa conmemorativa. Pero por estas fechas y diez años después tan solo consta documentalmente en las Actas Capitulares de 1566 una serie de actuaciones de escasa entidad: colocación de un toldo de madera en la ventana del cabildo; arreglo de las vidrieras de las ventanas de la sala de cabildo; mudar la puerta que está en dicha sala y ponerla en el corredor y finalmente se cita el arreglo de tejados de esta parte del cabildo (Jiménez 1987: 335-407).

Por otro lado aunque Henríquez no aclara en que consistió la reedificación de 1626, la documentación capitular de principios del siglo XVII refleja ante todo una creciente preocupación por el ornato del cabildo. En 1604 se habla de actuaciones sobre la alberca del cabildo, y en 1614 se acordó "reparar la sala baja del Cabildo" con obras de escasa entidad dado que el trabajo finalizó en un mes, librándose en noviembre cierta cantidad para "acabar los doseles" de dicha sala. Por tanto las reformas de 1554 y 1626 recogidas en las desaparecidas inscripciones de la fachada parecían referirse a la mejora de aspectos parciales del edificio o al reparo de los desperfectos de su fábrica más que a documentar una reedificación en sentido estricto. Mientras no aparezca una documentación que indique lo contrario hemos de barajar esta hipótesis (Cruz y Gómez-Moreno 2007: 60).

Posteriormente sí hay referencias documentales sobre una intervención sobre el edificio realizada en torno a 1665 y que hace alusión a la reparación de la sala baja del cabildo, donde se nos confirma por la descripción del lugar que esta sala es el actual oratorio islámico. Obras que son tasadas en 5.500 reales, aunque en realidad en 1665 solo se realizó por cuantía de 200 reales el aderezo de esta sala consistente en quitar cascajos del huerto colindante, reparar las jambas, apretar las quicialeras y los vuelos del "ochavo del tejado principal y el tejado de la pechina de enfrente como se entra por la puerta hacia la parte del huerto" (Cruz y Gómez-Moreno 2007: 62).

En definitiva y según los datos documentales localizados, las casas del cabildo durante los siglos XVI y XVII aún conservaban gran parte de su integridad y riqueza ornamental respecto de lo que fue la madraza. Conocemos dos copias de las inscripciones que contenía el edificio, procedentes ambas de una sola traducción y que fueron publicadas por Juan Velázquez de Echevarría en sus "Paseos por Granada y sus contornos". En estos textos el erudito relata la inscripciones que existían en el edificio y que fueron copiadas en 1556 por encargo del ayuntamiento en un manuscrito hoy perdido y del que él poseía una copia. Estos documentos también fueron conocidos por Leopoldo Eguilaz y pasaron a manos igualmente de Almagro Cárdenas. 
En la obra citada el P. Echavarría nos aporta una descripción del edificio y sus posibles estancias, aunque de una manera confusa y ambigua, basándose en las inscripciones que cada espacio contenía y que debían conservarse en el edificio durante el siglo XVI. Dentro de este recorrido nosotros solo nos vamos a centrar en los comentarios que menciona en alusión a las inscripciones situadas en la sala del cabildo,... "En el aposento principal donde fe celebraban los Cabildos, que fin duda ferviria de Aula en tiempo de los Moros, a los lados de la puerta del avia dos pequeñas ventanas; fobre ambas eftaba una Infcripcion repetida" (Velázquez 1993: 331), aunque no deja claro si esta sala se encuentra en la planta alta o baja.

Almagro Cárdenas en su descripción tomada del mismo manuscrito de 1566, es bastante más explícito con respecto a la ubicación de esta sala:

La escalera, cuya puerta acabamos de describir, daba a unos corredores con arcos sostenidos por bien labradas columnas, del mismo gusto y análoga forma a las correspondientes de la planta baja. Sobre los capiteles de las mismas, en los arcos que sostenían en las paredes de los cuatro lados...Conducían estos corredores al aula principal que después se convirtió en salón de sesiones del Municipio (Cruz y Gómez-Moreno 2007: 87).

Manuel Gómez-Moreno González en su "Guía de Granada" vuelve a aludir también a estos documentos que recogían las citadas transcripciones. Según este autor en el manuscrito se llamaba palacio a la habitación o sala principal que servía en verano para los cabildos; en ella, sobre las ventanas que tendría encima la puerta y hacia los rincones, leíanse pasajes del Corán; los azulejos de su zócalo remataban en una faja con el "Sólo Dios es vencedor" y "el reino a Dios único"; encima había paños de yesería con pequeñas salutaciones en escuditos, los cuales terminaban en otra cenefa con el mismo lema de los reyes que también se repetía en el alicer de su techumbre. En el testero de la habitación dicen que destacaba un gran amuleto cabalístico formado por combinación de diversas letras y palabras, que creían tener virtud para producir la ciencia infusa (Gómez-Moreno 1994: 311-312).

Parece que los tres autores hablan de la misma sala. En el caso del P. Echevarría sin ubicarla en una planta u otra, y en el de Gómez-Moreno indicándonos que dicha sala debía de servir de reunión del cabildo para el verano, lo que la situaría en planta baja y nos daría a entender que está hablando del oratorio. En cualquier caso la descripción que hace Gómez-Moreno tenía incoherencias pues era conocida la existencia de escaleras en el conjunto y el autor deduce que el edificio no debía de tener planta alta, pues en los documentos no se describen ornamentaciones situadas a ese nivel. A este respecto el P. Echevarría habla unos párrafos antes de describir la sala en cuestión de los detalles de ornamentación e inscripciones existentes en la puerta principal de la escalera. Esta línea secuencial nos induce a suponer que todas las partes que describe con posterioridad a la escalera están en planta alta. Esta conclusión nos quedaría verificada con los datos que nos aporta Almagro Cárdenas, donde deja constancia clara de que la supuesta sala se situaría en planta alta.

\section{La desaparición de la madraza nazarí y la nueva sede capitular (1720-1858)}

El viejo edificio consistorial granadino, mezcla de espacios nazaríes y añadidos quinientistas, será remodelado por completo en el primer tercio del siglo XVIII. Tales reformas, que pueden sin pudor catalogarse como reedificación, reconstrucción o remodelación profunda, cambiaron por completo la fisonomía del inmueble otorgándole en gran parte la imagen característica que hoy posee. Las razones de estos profundos cambios debieron ser de índole ideológica y representativa, buscando sumarse a la redefinición cultural del centro urbano e institucional como ciudad clasicista pero también de índole funcional, pues el mal estado del inmueble debía de ser acuciante. El deterioro del conjunto de la casa del cabildo queda manifiesto en un documento de 1720 del Archivo Histórico de Granada según testimonio del portero José Sánchez:

Las Casas del Cabildo están maltratadas, que por lo interior de ella donde están las oficinas están amenazando ruina, de suerte que es incapaz de entrar en los dichos cuartos y sitios donde están, además del mal olor que causa en el todo el barrio, y si no se remedia está próximo a suceder muchas desgracias, demás que no se podrá celebrar la muestra de autos en el patio ni poner el toldo por el referido peligro inconveniente (Cruz y GómezMoreno 2007: 63).

Ante aquella denuncia ese mismo año el maestro de la ciudad Nicolás de Valverde reconoció el edificio declarando que era preciso "desenvolver los tejados, 
corredores y corinas (¿cornisas?), componer la madera que va por dichas casas y empedrar el patinillo y recomponer la cañería"; trabajos estos que con un coste de 1.913 reales fueron concluidos en un plazo de unos dos meses. Un nuevo parcheo que induciría a pensar en la necesidad de resolver de una forma más adecuada la renovación el inmueble, optándose finalmente por una serie de decisiones encadenadas que a la postre implicaron el derribo o supresión de varios espacios (Cruz y Gómez-Moreno 2007: 63-64).

Pues bien, poco después de 1720 debió ya trabajarse casi ininterrumpidamente en la madraza, como se deduce de la inscripción existente sobre la actual portada donde se alude a la reedificación y adorno de las casas capitulares en el año 1722. A pesar de la importancia de las transformaciones que tuvieron lugar a partir de entonces en el edificio apenas se conserva documentación histórica acerca de las mismas, salvo algunas anotaciones recogidas a finales del siglo XIX por Manuel Gómez-Moreno González sobre textos que el mismo transcribió. El mencionado historiador apunta que en el año 1722 "se renovó la fachada del ayuntamiento antiguo", y también debió de acometerse según Real Cédula de 1725 "la reedificación de la sala capitular alta y sus adornos". Este mismo proyecto alcanzaría a la construcción de un nuevo ámbito interior, la sala capitular baja, cuya construcción se pospuso a 1725 .

Con respecto a la actuación que supuso la reedificación de la sala capitular alta los sondeos arqueológicos nos proporcionan datos muy relevantes. El patio es reducido en su parte norte y oeste en la segunda fase cristiana, es decir segunda mitad del siglo XVII-primeras décadas del XVIII. De tal manera que se configura un nuevo complejo estructural con sus respectivas paredes. Reducción que se achaca en este estudio arqueológico a la reedificación del Salón de Caballeros XIV en la planta superior para apoyo de descarga en la planta inferior (Malpica et al. 2015: 327-330).

Volviendo a la propuesta de realizar la nueva sala capitular baja, la cantidad disponible para su ejecución ascendía a 4.000 ducados, más que suficiente para añadir un nuevo espacio al inmueble. Según un informe del maestro Daldá Pérez del 5 de marzo de 1725 la nueva sala capitular de verano debería tener 8 varas de ancho y 17 de largo, y su altura de 9 varas desde la solería hasta las claves de la bóveda de arista que la cubriría, siendo iluminada por cuatro ventanas carceleras, dos a cada lado. Dicha sala se iba a construir ocupando parte de un jardín solar, y todo parece indicar que la nueva sala podría coincidir con el hasta hoy Salón de Exposiciones en atención a las medidas expresadas y a la posición relativa que ocupaba (Cruz y Gómez-Moreno 2007: 64-65).

La documentación copiada por Gómez-Moreno González aclara el ritmo y las vicisitudes de los trabajos, que indujeron finalmente al cabildo a emprender una obra de mayor calado que implicaba la práctica desaparición de la madraza islámica. Puede decirse por tanto que los trabajos de remodelación del inmueble se realizaron en dos fases diferentes: la primera en torno a 1722 con la reconstrucción ex novo de la fachada en su parte occidental y su nueva portada y la reedificación de la sala capitular alta; y la segunda y más profunda a partir de 1725, que afectaría al resto del edificio tanto en la parte de fachada que restaba como en su interior.

Las obras fueron adjudicadas al mencionado maestro mayor Manuel Daldá Pérez y al maestro de albañilería Manuel Moreno Hermoso por cuantía de 55.000 reales, excediendo en 15.000 reales la cantidad asignada en 1723 . Pero apenas iniciados los trabajos, en 1725 el corregidor don Juan Jerónimo de Blancas junto al comisario para dicha obra don Juan de Paz Brizmán dan cuenta de que "se estaba cayendo la casa en que se hacía la sala principal y otras estancias y que con lo que había de gastarse en reedificarla se podría acabar la fachada de las Casas Capitulares, cuya obra tendría menos coste que lo que necesitaba la casa" (Cruz y Gómez-Moreno 2007: 66).

Según se deduce de esta cita, la fachada distaba de estar terminada, y por otro lado al romper uno de los muros de la antigua madraza para la ampliación del edificio se hizo evidente el mal estado de su estructura, por lo que se pensó ya más en su demolición que en su ulterior reforma. Además la casa colindante perteneciente al cabildo catedralicio había sufrido daños en sus paredes causando la desunión de la esquina que hacía frente a la Lonja.

El 9 de agosto de 1725 el maestro mayor Daldá Pérez vuelve a presentar otro informe que nos aclara el alcance de las intervenciones finales sobre el conjunto. Por su interés documental he aquí la transcripción realizada por Gómez-Moreno González del documento original:

Visto y reconocido las Casas Capitulares después de haber planteado la Sala Baja de verano y haber sacado sus cimientos y respecto de lo incómodo de dichas casas y lo imperfecto de ellas, por no estar concluidas así en lo exterior como en lo interior, por faltar bastantes piezas, como son la antesala-oratorio; que la placeta es muy pequeña...; lo impropio de su fachada de dichas casas, por no estar hecha más de la mitad de ella, por cuya razón está 
la puerta en un rincón; y para que este con la perfección que requiere y corresponde; es necesario demoler lo que está contiguo a ellas, que es de los Propios de ella y a ellas destinado, que por ser mala fábrica y muy antigua, pues lo mas de ella es de tapias de tierra y de lo primitivo de esta ciudad y estar amenazando ruina, es necesario demoler la mayor parte de ella, como es todo el cuarto principal de la calle, para volverlo a edificar desde los cimientos, por estar todo quebrantado y desnivelado. Es necesario correr la fachada hasta en cantidad de 14 varas, que es lo que le falta para que quede con la perfección que requiere dicha obra, hechándole dos balcones que también le faltan a la fachada y dejarla enteramente concluida. También es preciso hacer la escalera, que la que hay es muy estrecha, siendo de 4 varas de ancho la que se haga, de dos idas con una meseta. Dejando la fachada enteramente rematada según y cómo está ejecutada la otra media y la escalera con la conformidad que lleva, tendrá de costo 105.000 reales (Cruz y Gómez-Moreno 2007: 66).

Es decir, lo que se planteaba era la supresión del cuarto principal, refiriéndose probablemente a la sala que el P. Echevarría, Almagro Cárdenas y el propio GómezMoreno González definían en párrafos anteriores como el Aula de enseñanza; actuación que también se extendía a la fachada y la escalera de la madraza nazarí. En 1722 se había realizado la fachada y portada del área relativa al Salón de Caballeros XXIV donde se encuentra en la actualidad; de ahí que el texto mencione que dicha portada se hallaba en un rincón. La propuesta consistía en terminar las 14 varas de largo de fachada que quedaban por igualar a nivel estético con los dos balcones más meridionales, construir una nueva escalera -lo que afectaría lógicamente al conjunto del patio-, construir la nueva sala baja capitular proyectada y redecorar con yeserías el ámbito usado hasta entonces como tal, el viejo oratorio nazarí. El 11 de agosto de 1725 se mandó demoler lo ruinoso y proceder a las obras señaladas. Aunque, según el citado manuscrito de Gómez-Moreno González, la sala baja no se terminó sino el año 1728 a tenor de la lauda en mármol negro dedicatoria de la escalera donde se cita la construcción de la nueva escalera, patio y sala baja y con la extensión de la antesala alta, oratorio y sacristía, refiriéndose quizás a la sala ubicada en la misma crujía frente al Salón de Caballeros XXIV.

En definitiva, el edificio de las viejas casas del cabildo, mezcla de espacios nazaríes y añadidos quinientistas, será remodelado por completo entre la década de 17201730. A partir de este momento habrá que esperar hasta el último tercio del siglo XVIII para tener constancia de nuevas intervenciones materiales sobre el mismo. De entre todas ellas cabe destacar el mal estado de los tejados de la antesala y sala baja capitulares al que hubo de unirse el deterioro de la cubierta de la sala alta del cabildo:

Los tejados que se hallan sobre las Salas Altas capitulares de la fachada exterior o principal están arruinados y suma necesidad de que se remedien inmediatamente, por ser muchas las goteras que se advierten en las mismas salas y sobre los asientos de terciopelo que se hallan en ellas... asimismo hace presente que el rimillo (sic) de la fachada del patio principal de dichas casas se ha bufado con la humedad y mala construcción que tenía, de forma que se halla en unos términos irrisibles y contra la magnificiencia de dichas casas (Cruz y Gómez-Moreno 2007: 70).

Tras la renovación de cubiertas y de los cenadores del patio de finales del siglo XVIII ya no se tiene conocimiento documental de más obras realizadas en el edificio hasta su supresión como casa del cabildo a partir de 1858 . Con posterioridad a esta fecha evidentemente el edificio ha ido sufriendo obras de mejora y acondicionamiento hasta llegar a su restauración integra en la primera década del siglo XXI; pero ninguna de ellas le ha supuesto transformaciones de trascendencia a la estancia protagonista de este texto: el Salón de Caballeros XXIV.

\section{ANÁLISIS E INTERPRETACIÓN DE LA EVOLUCIÓN CONSTRUCTIVA DE LA SALA ALTA DEL CABILDO Y SU ARMADURA}

Una vez relatados los principales datos históricos del devenir constructivo del conjunto de las casas del cabildo, volvemos al punto de partida y objeto de esta publicación: el análisis e interpretación de la evolución constructiva de la sala alta del cabildo llamada Salón de Caballeros XXIV, y de su armadura.

La ubicación primigenia de esta sala nos genera ciertos reparos si partimos de las citas históricas que hasta el momento se conocen. Las primeras actuaciones que se llevan a cabo en el edificio islámico consisten en adquirir unas casas aledañas en su flanco occidental con el objetivo de ampliar el conjunto para su nuevo uso de casa del cabildo. Pues bien, según los textos estas viviendas probablemente son demolidas o bien sufren obras en su composición de cierta entidad, pero lo que no acaban de 
aclarar es si el cuerpo constructivo que se crea es destinado en su planta superior a la sala alta del cabildo.

Por otra parte y en paralelo, la madraza debía de contar en su distribución original con un espacio o espacios destinados a sala de enseñanza. Esta Aula, de cuya existencia y partiendo siempre de interpretaciones nos dejan constancia los autores que relatan las transcripciones que el edificio debía de contener hasta mediados del siglo XVI, se localiza a la izquierda de la entrada según el plano de hipótesis de planta baja recogido en el estudio arqueológico realizado recientemente (Fig. 4). Desconocemos si esta sala tuvo una o dos plantas en su origen y obviamente qué tipo de techumbre pudo ostentar.

Como última variable y verdadero protagonista de este análisis, se encuentra el artesonado que hoy en día cubre el Salón de Caballeros XXIV. Estructura lígnea no descrita hasta el momento pues las fuentes históricas no se hacen eco de su creación. Se trata de un magnífico ejemplar de armadura rectangular ochavada con perfil de limas moamares. Los pares aparecen apeinazados en los arranques con lazo de ocho y se cruzan hacia la mitad de la calle. El almizate va completamente apeinazado con lazo estructurado en torno a tres estrellas de ocho puntas. También aparecen los tirantes pareados sobre canes lobulados y labor de lazo. Todo aparece decorado con pinturas, probablemente de la mano del pintor Francisco Fernández en el año 1513. Los pares, nudillos y limas llevan perfiles pintados con ocre y blanco en el centro. La tablazón tiene complejo programa de grutescos, muy del gusto plateresco, dominado por tonos azules, blancos y rojos. En las calles de los pares aparecen pintadas cabezas humanas de hombre y mujer (López y Henares 1987: 519).

Esta armadura, por su diseño y la creencia recogida en la mayoría de textos editados de que su ejecución pertenece a los primeros años del siglo XVI, ha sido siempre definida como un artesonado propio del arte mudéjar con decoración plateresca. Pero esta teoría tan consensuada hasta el momento nos suscita dudas tras interpretar los datos históricos y analizar su metrología (Fig. 16).
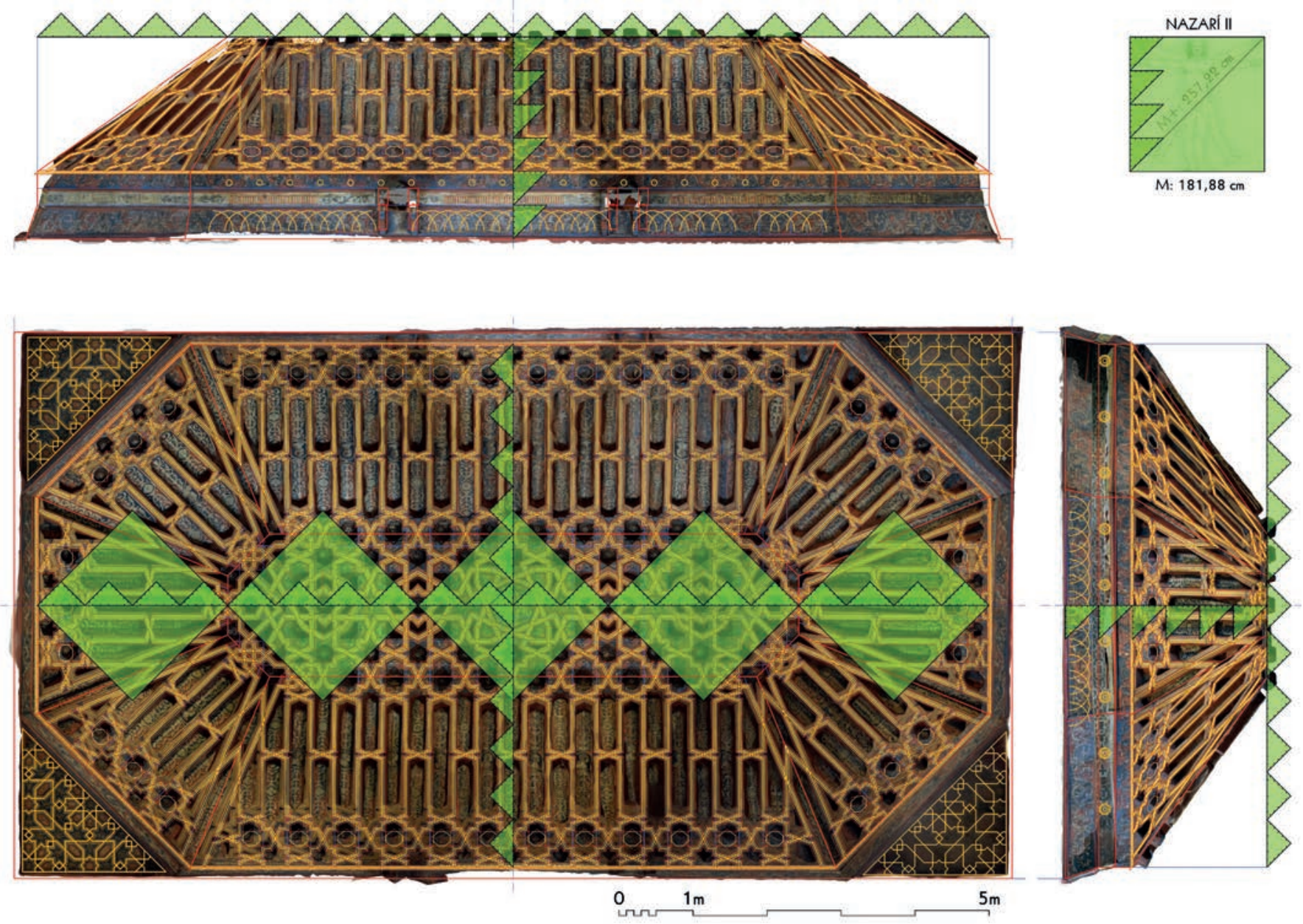

Figura 16. Modulación de la armadura. 
Estas incertidumbres se nos acrecientan aún más cuando reparamos en la superficie que abarca la armadura, mucho mayor a la contenida por las viviendas aledañas, lo que obligaría en su momento a plantear el derribo de parte del muro lindante de la madraza, pues el límite exterior del edificio estaba condicionado urbanísticamente por la existencia de la calle Oficios. Actuación que no damos por descartada pero que parece poco razonable si partimos de la existencia en el edificio de una sala, el Aula, cuya entidad espacial y ubicación a fachada podría cumplir con el objetivo de destinarla al uso de sala alta del cabildo, limitándose la actuación a un acondicionamiento de este espacio para otorgarle una imagen más acorde a la nueva sociedad cristiana, y a la construcción de un forjado si es que solo tenía una única planta. Esta posibilidad nos genera unas conclusiones inmediatas con respecto a su techado en planta alta que pasarían por considerar que esta armadura podía preexistir en estos primeros años del cabildo, y que la actuación se reduciría al redecorado de la estructura que incluiría el pintado de esta con un claro gusto plateresco. Esta suposición encajaría a su vez con las dimensiones que el plano de distribución original le otorga al Aula, pues la superficie de la armadura coincide con la de la sala en cuestión, lo que nos permite intuir que en esta hipótesis de planimetría planteada tras el estudio arqueológico debió de barajarse esta posibilidad de distribución del edificio islámico, aunque el documento en cuestión no sea explícito al respecto.

Evidentemente una vez llegados a la segunda etapa evolutiva del edificio donde se resuelve la transformación íntegra del edificio en el siglo XVIII, se decide trasladar la sala alta del cabildo junto a su armadura al lugar donde actualmente se sitúa el conjunto (ver Figura 3). Actuación claramente representativa pero también de índole funcional. La sala alta, lugar de reunión de los veinticuatro caballeros, por su claro carácter simbólico precisaba de una posición en el inmueble que le habilitase obtener la mayor longitud posible a fachada. La zona donde suponemos se ubicó en el siglo XVI, por su mal estado de conservación y entre otras razones por alegarse en los documentos que era de tapial, debía de demolerse. Por último el edificio requería de la construcción de unas nuevas escaleras de mayor entidad pues las preexistentes islámicas eran muy estrechas para un edificio institucional que debía mostrarse a la ciudad con una estética claramente clasicista. El replanteo de esta nueva estructura precisaba de parte del espacio que hasta ese momento había ocupado la primitiva Aula.

Todos estos factores, entre otros, debieron de condicionar reubicar la sala alta aprovechando la reconstrucción casi total del inmueble. Esta nueva ubicación en la esquina, donde actualmente se encuentra, obligaba a ocupar parte del patio por las dimensiones que necesitaba un espacio de esta entidad y condicionado por la superficie de la armadura a trasladar. De este modo se creó una solución que obligó a reducir el patio en su parte norte y oeste para poder descargar el apoyo en la planta inferior de las paredes de la nueva sala superior, lo que ha permitido atestiguar y confirmar esta obra según los sondeos arqueológicos datándola entre la primera mitad del siglo XVII-primeras décadas del XVIII.

Todas estas conjeturas nos llevan a plantearnos que el artesonado de la sala alta del cabildo pudo ser en realidad una armadura nazarí que cubría en su origen el Aula de enseñanza de la madraza, que posteriormente es redecorada a principios del siglo XVI para otorgarle una imagen artística protorrenacentista, y que finalmente es trasladada en las primeras décadas del siglo XVIII a su actual posición cuando se decide la reedificación del edificio. Hipótesis que en su conjunto se ajustaría a los resultados del estudio métrico de dicha estructura lígnea presentado en este artículo (Fig. 17).

La conjunta relectura de los datos recopilados permite ofrecer también una localización alternativa de esa hipotética Aula de la madraza cubierta por esta armadura. Este espacio podría haberse situado igualmente entrando a la izquierda, pero en posición paralela a la fachada principal tal como presenta en la actualidad el Salón de Caballeros XXIV. De esta manera el largo del Aula encajaría entre el muro izquierdo del actual vestíbulo y el lindero izquierdo del inmueble señalado por el actual retranqueo, o entre el muro medieval localizado en medio del vestíbulo actual y la prolongación del muro de fondo de la actual escalera.

La construcción solo de parte de la fachada en la esquina correspondiente al Salón de Caballeros XXIV en la primera intervención del siglo XVIII -"la reedificación de la sala capitular alta y sus adornos"- pudo estar condicionada por el interés en reubicar la magnífica armadura que hasta entonces cubría el Aula de la madraza nazarí, lo que implicaba tener que reproducir antes un espacio con similares dimensiones. Dado que el ancho necesario coincide con el del testero de la sala baja -cubierta por el alfarje del siglo XVI- debió elegirse aprovechar su obra y alineación para el emplazamiento de la nueva sala, a pesar del descuadre de la medianera 


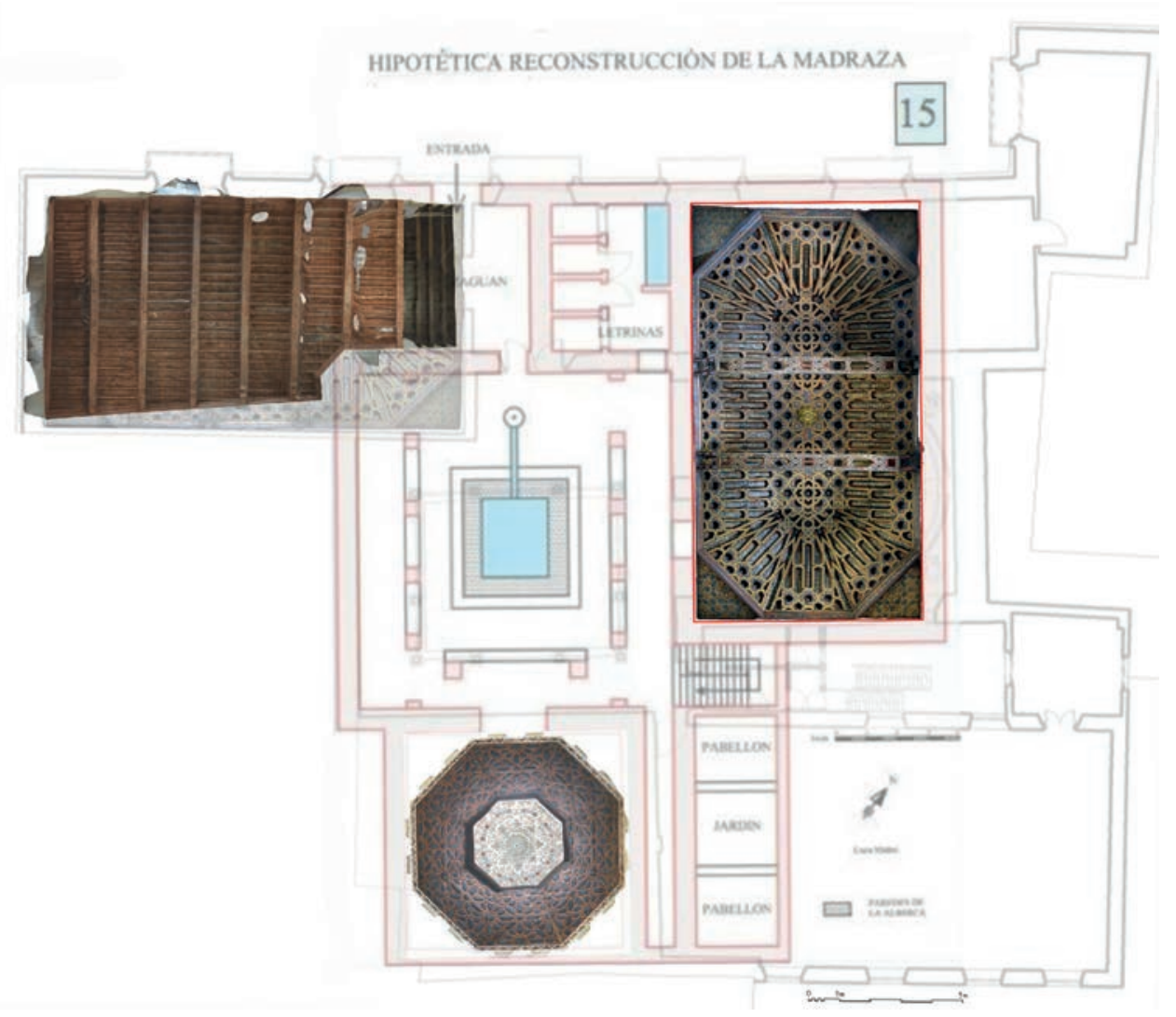

Figura 17. Hipótesis de localización del Aula de la Madraza con su armadura. y de la invasión del patio y vestíbulo ya mencionados.

Esta actuación supuso también la demolición de la portada original de la madraza. La nueva se alineó con la obra del alfarje y ahora nuevo salón, y parece ser que se retranqueó de su posición inicial para dar más espacio a la placeta. Pudo incluso localizarse la portada original en el mencionado retranqueo, dando frente a poniente y con entrada en recodo como parece representarse en la Plataforma de Vico (ver Figura 1).

Una vez concluida la "reedificación" y traslado de la armadura pudo acometerse la segunda y más profunda intervención. El cuerpo de la antigua Aula, desposeído de cubierta y adornos, ocupaba aún buena parte de la fachada y producía con su mayor ancho el retranqueo "por cuya razón está la puerta en un rincón".

Frente a esta hipótesis nos encontramos sus detractoras basadas en las propias fuentes editadas, que han consolidado de manera constante en el tiempo que la sala alta del cabildo fue creada desde su origen en el edificio aledaño que se anexiona al original. Por otro lado las madrazas conservadas en el norte de África no disponen de grandes salas mayores que el oratorio. Además hay que unir la teoría también muy arraigada de que las armaduras nazaríes no contenían tirantes, entre otras razones por la ausencia de estos en el recinto de la Alhambra. Postulado que entra en contradicción con la existencia hoy en día conocida de varias armaduras nazaríes con tirantes dobles, como la de la sala alta del Palacio de Dar al-Horra, o la de los Baños de Comares en la misma Alhambra.

De hecho los resultados antropométricos y preliminares de otras armaduras granadinas consideradas modernas cuestionan su datación y origen (Fig. 18). Así el ejemplar con tirantes dobles y ligera labor de lazo que se conserva en el vestíbulo de planta primera del reedificado Palacio de los Córdova presenta métrica Nazarí II, y al igual que el estudiado está decorado con pinturas platerescas. Por su parte el del Cuarto Real de Santo Domingo presenta métrica Nazarí I, el de la sala norte del Generalife métrica Nazarí II, el cercano del Colegio de Niñas Nobles tiene medida Castellana y el existente en la escalera del Convento de Santa Paula es de métrica Toledana, coincidiendo con el periodo histórico que cada uno tiene asignado.

Ante las teorías prefijadas por gran parte de los investigadores y claramente contrarías a nuestra principal hipótesis, cabe la posibilidad de plantearnos una segunda que se alejaría en gran medida de nuestras propias convicciones pero que sería compatible con las más 

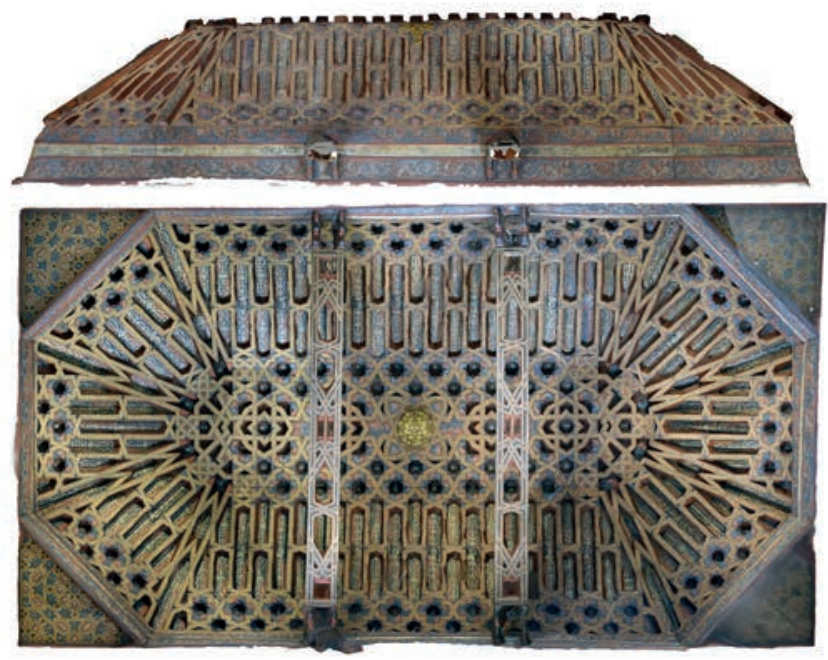

a)
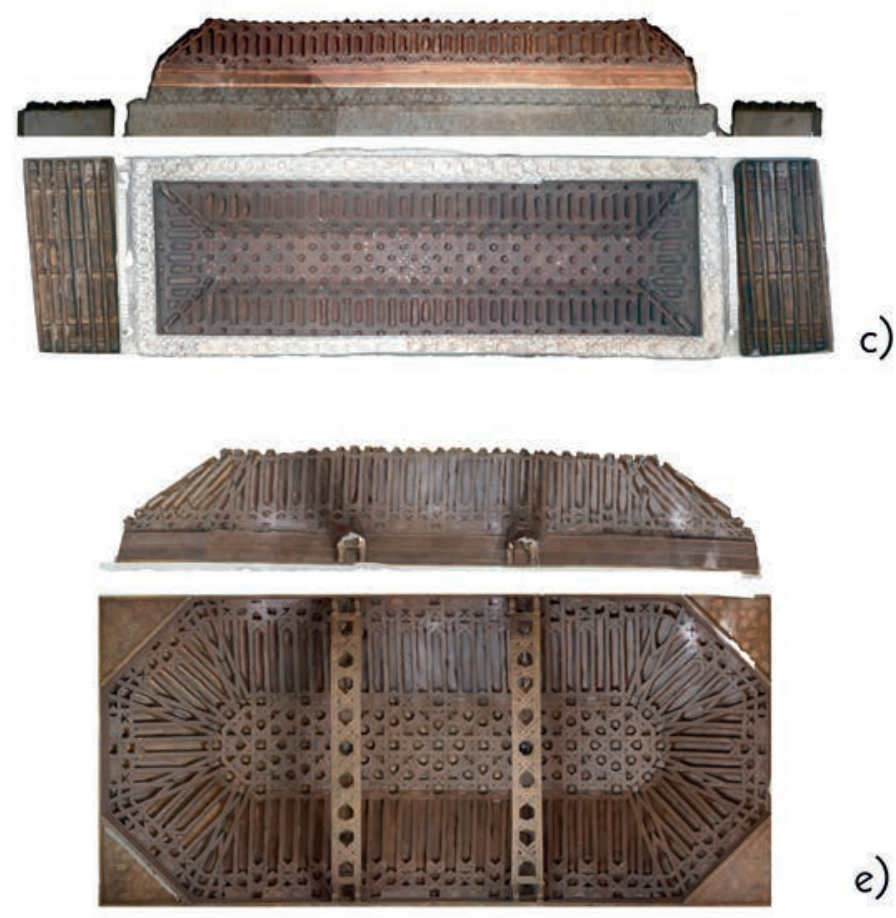

e)
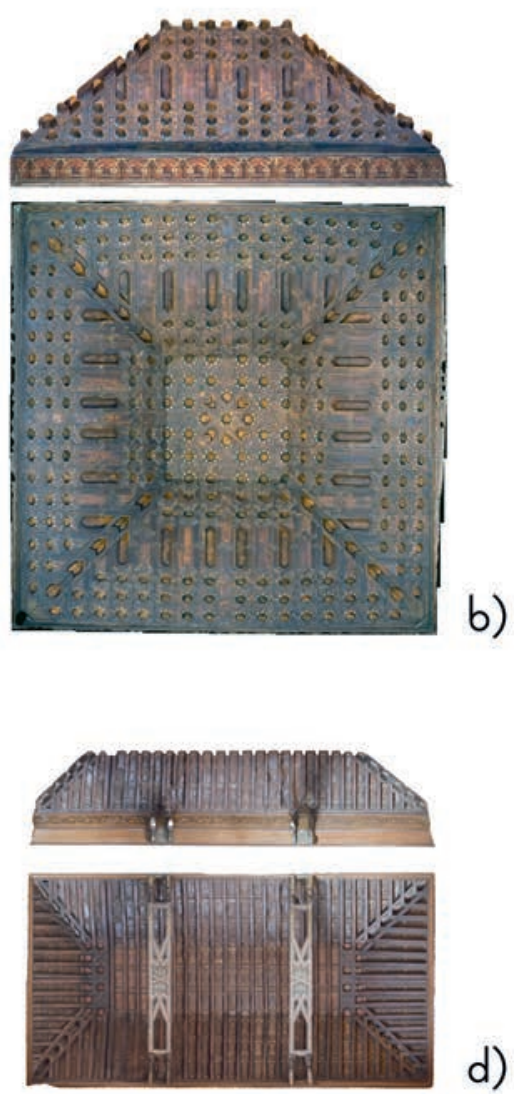

d)
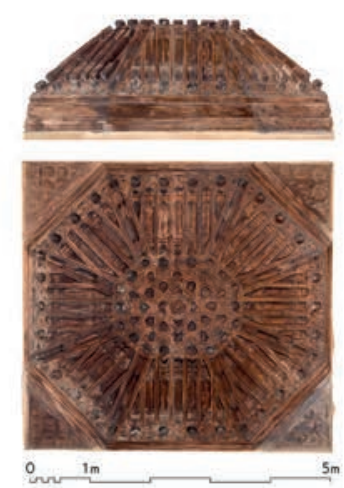

f)

Figura 18. Ortofotos de armaduras granadinas. a) Salón de Caballeros XXIV en la Madraza; b) Cuarto Real de Santo Domingo; c) Salón norte del Generalife; d) Palacio de los Córdova; e) Colegio de Niñas Nobles; f) Convento de Santa Paula.

ortodoxas. Se trataría de sugerir la posibilidad de que la armadura realmente se crease en la primera década del siglo XVI de la mano de carpinteros musulmanes, en este caso con independencia de su ubicación aunque sería más lógico situarla desde un principio en su posición actual. El desconocimiento técnico para ejecutar este tipo de armaduras de lazo por parte de los nuevos maestros debía de ser natural en estos primeros años tras la conquista de la ciudad. El barajar esta posibilidad nos derivaría a considerar que estos maestros musulmanes, durante un periodo corto de tiempo que podríamos denominar de transición, se les permitiese construir siguiendo sus propias medidas.

Ambas hipótesis no cuestionan en ningún sentido el origen del alfarje inferior que cubre la planta baja del edificio, y que en su origen fue añadido a la madraza 
original. No hemos obtenido documentación histórica que aclare la función de esta sala, aunque las citas nos inducen a pensar que esta estancia inferior fue la denominada Audiencia. Dada la calidad de tales alfarjes aunque algunas partes muestren reformas o reposiciones posteriores-e incluso la presencia de restos de policromía, es plausible pensar que debieron cubrir espacios con alguna función lo suficientemente importante o representativa tales como salas de audiencia civil o escribanías. Este forjado debió de construirse a principios del siglo XVI, y su métrica Castellana respondería a que nos encontramos con una estructura que para su construcción no necesitaba de manos especializadas, pues su ejecución era de menor complejidad frente a la de una armadura decorada mediante el sistema de lacería.

En cualquier caso para poder verificar cualquiera de las dos hipótesis aquí presentadas se demandaría de más estudios paralelos que hasta el momento no se han llevado a cabo. La analítica material de la estructura lígnea nos podría aportar datos cronológicos de la madera contenida en la armadura para poderle dar luz a la primera. Estudios de metrología en otras armaduras de similares características, ubicadas en otros edificios de la ciudad y cuya datación pudiese encajar también en este periodo de transición, servirán para profundizar con respecto a la segunda.

\section{CONCLUSIONES}

Intentando sintetizar los resultados de esta investigación debemos admitir que frente a la hipótesis de la reutilización y traslado de la armadura desde una supuesta Aula de la madraza existen los siguientes fundamentos:

- Las fuentes documentales publicadas.

- La inexistencia de grandes aulas en las madrazas del norte de África.

- La pendiente de la armadura y la presencia de tirantes propias de obras cristianas.

A favor de plantear esta teoría debemos hacer constar:

- Los resultados de la Antropometría.

- La hipótesis publicada en un estudio arqueológico.

- Las fuentes primarias, que avalan "la reedificación de la sala capitular alta y sus adornos" a principios del siglo XVIII.
- Los desajustes del diseño de la armadura respecto de las reglas "Arenas".

- La forzada e invasiva implantación constructiva de la sala.

Aparte de plantear la posibilidad intermedia de que se trate de una obra mudéjar con métrica "antigua", se señala la similitud de la armadura con otros ejemplares de la ciudad, y el interés tanto de realizar estudios de datación absoluta mediante técnicas convencionales como de emplear el nuevo método de análisis antropométrico para la interpretación correcta de este patrimonio.

\section{AGRADECIMIENTOS}

Las cordiales entrevistas que nos concedieron Antonio Orihuela Uzal, Pedro Salmerón y Luca Mattei aportaron documentación e información de primera mano para los objetivos del presente estudio.

\section{FICHA TÉCNICA}

Figuras 5-18. Francisco Javier Roldán Medina

\section{BIBLIOGRAFÍA}

Almagro Gorbea, A. 2007. "Levantamiento planimétrico del Palacio de la Madraza”, en R. López Guzmán y M. E. Díez Jorge (eds.), La Madraza: pasado, presente y futuro, pp. 323-334. Universidad de Granada.

Cruz Cabrera, J. P. y Gómez-Moreno Calera, J. M. 2007. "Estudio históricoartístico del palacio de la Madraza, antigua casa del cabildo de Granada", en R. López Guzmán y M. E. Díez Jorge (eds.), La Madraza: pasado, presente y futuro, pp. 43-137. Universidad de Granada.

García Valenzuela, H. 1988. Índices de los libros de cabildo del Archivo Municipal de Granada: 1497-1518. Universidad de Granada.

Guerrero Lafuente, M. D. 2007. La memoria de la ciudad: el segundo libro de actas del cabildo de Granada (1512-1516), vol. I y II. Universidad de Granada.

Gómez-Moreno González, M. 1994. Guía de Granada, vol. I. Universidad de Granada.

Gómez-Moreno Martínez, M., Moya Morales, J. y López Pertíñez, M. C. 2001. La carpintería de Granada. Instituto Gómez-Moreno de la Fundación Rodríguez-Acosta, Granada.

Jiménez Vela, R. 1987. Índices de los libros de cabildo del Archivo Municipal de Granada: 1518-1566. Universidad de Granada.

Lafuente Alcántara, M. 1986. El libro del viajero en Granada. Don Quijote, Granada.

López Guzmán, R. y Henares Cuéllar, I. L.1987. Tradición y clasicismo en la Granada del XVI: arquitectura civil y urbanismo. Diputación Provincial de Granada.

López Pertíñez, M. C. 2006. La carpintería en la arquitectura nazarí. Instituto Gómez-Moreno de la Fundación Rodríguez Acosta, Granada. 
Malpica Cuello, A. y Mattei, L. 2015. "Una hipotética reconstrucción”, en Malpica Cuello A. y Mattei L. (eds.), La madraza de Yusuf I y la ciudad de Granada. Análisis a partir de la arqueología, pp. 335-338. Universidad de Granada.

Malpica Cuello, A., Mattei, L., Martín Civantos, J. M., González Escudero, A. y Ruiz Jiménez, A. P. 2015. "Periodización y fases a partir del análisis histórico arqueológico de la Madraza", en Malpica Cuello A. y Mattei L. (eds.), La madraza de Yusuf I y la ciudad de Granada. Análisis a partir de la arqueología, pp. 299-333. Universidad de Granada.

Mattei, L. 2008. "Estudio de la Madraza de Granada a partir del registro arqueológico y de las metodologías utilizadas en la intervención del 2006". Arqueología y Territorio, 5, pp. 181-192.

Moreno Trujillo, M. A. 2005. La memoria de la ciudad: el primer libro de actas del Cabildo de Granada (1497-1502). Universidad de Granada.

Nuere, E. 1985. La carpintería de lo blanco. Lectura dibujada del primer manuscrito de Diego López de Arenas. Ministerio de Cultura, Madrid.

Nuere, E. 1989. La carpintería de armar española. Ministerio de Cultura, Madrid.

Roldán Medina, F. J. 2011. La escuadra sagrada. Bubok, Madrid.

Roldán Medina, F. J. 2012a. "Modulación, tipología de tramas y ajuste a los límites en la metrología arquitectónica clásica”, EGA: Revista de Expresión Gráfica Arquitectónica, (20), pp. 172-183. https://doi. org/10.4995/ega.2012.1448

Roldán Medina, F. J. 2012b. "Method of Modulation and Sizing of Historic Architecture", Nexus Network Journal, 14 (3), pp. 539-553. https://doi. org/10.1007/s00004-012-0125-5

Roldán Medina, F. J. 2012c. "Método de modulación y dimensionado de la arquitectura histórica". Actas de AR\&PA 2012: VIII Bienal de la Restauración y Gestión del Patrimonio. Junta de Castilla y León.

Roldán Medina, F. J. 2013. "Combinación de módulos en la metrología clásica”. VAR: Virtual Archaeology Review, 4 (9), pp. 82-92. https://doi. org/10.4995/var.2013.4252

Roldán Medina, F. J. 2014a. Principios de metrología en la arquitectura del pasado. Universidad de Granada.

Roldán Medina, F. J. 2014b. "El origen de la proporción en la arquitectura clásica...y su futuro", en D. Arredondo Garrido, J. Calatrava Escobar, A. D. Cid Mendoza y F. García Pérez (eds.), De la casa al territorio.
Jornadas de investigación en arquitectura, pp. 275-286. Universidad de Granada.

Roldán Medina, F. J. 2015a. “Análisis antropométrico de la mezquita-catedral de Córdoba", Informes de la Construcción, 67, 539, e093. https://doi. org/10.3989/ic. 14.024

Roldán Medina, F. J. 2015b. "La doble medida en la arquitectura del pasado: el Palacio de Onda y su planta antropométrica", Arqueología de la Arquitectura, 12, e023. https://doi.org/10.3989/arq.arqt.2015.005

Roldán Medina, F. J. 2015c. "Unraveling the Classic Proportions Through the Anthropometric Analysis of the Architectural Heritage. The Case of the Pantheon". Digital Heritage 2015. IEEE, Granada.

Roldán Medina, F. J. 2015d. Patrón de longitud elástico. Modelo de Utilidad ES 1139987 Y. No de solicitud U 201530453. Publicado BOPI 16/06/2015, Año CXXIX, núm. 4442. Fecha de concesión 01/09/2015.

Roldán Medina, F. J. 2015e. Estudio Antropométrico de la Fachada de Comares en la Alhambra. Patronato Alhambra y Generalife. Unpublished. https://doi.org/10.13140/RG.2.2.34705.43361

Roldán Medina, F. J. 2016. Estudios antropométricos del patrimonio. Finalista Convocatoria Investigación en Arquitectura y Urbanismo. XIII Bienal Española de Arquitectura y Urbanismo.

Roldán Medina, F. J. 2017. "Nuevas herramientas métricas para el estudio del patrimonio arquitectónico”, en M. Palma Crespo, M. L. Gutiérrez Carrillo y R. García Quesada (eds.), Reuso Granada 2017. Sobre una arquitectura hecha de tiempo, pp. 275-280. Universidad de Granada.

Roldán Medina, F. J. 2018a. "Geometría y métrica en la planta circular del Palacio de Carlos V”, en P. A. Galera Andreu y S. Frommel (coord.), El patio circular en la arquitectura del Renacimiento: de la Casa de Mantegna al Palacio de Carlos V, pp. 355-381. Universidad Internacional de Andalucía, Sevilla.

Roldán Medina, F. J. 2018b. "Datación Antropométrica Abierta", en L. Bocanegra Barbecho y E. Romero Frías (eds.), Territorios Digitales. Construyendo unas Ciencias Sociales y Humanidades Digitales. Libro de Resúmenes. Talleres y Mesas Temáticas, p. 199. Universidad de Granada. https://doi.org/10.5281/zenodo.1469330

Sarr, B. 2015. "La Madraza Yusufiyya en las fuentes árabes”, en A. Malpica Cuello y L. Mattei (eds.), La madraza de Yusuf I y la ciudad de Granada. Análisis a partir de la arqueología, pp. 51-55. Universidad de Granada.

Velázquez de Echevarría, J. 1993. Paseos por Granada y sus contornos, T. 1. Universidad de Granada. 